\title{
A Model of the Threats that Disreputable Behavior Present to Esports Sponsors
}

\author{
Bruno Duarte Abreu Freitas \\ Universitat de Vic - Universitat Central de Catalunya \\ E-Mail: brunoduarte.abreu@uvic.cat \\ Ruth Sofia Contreras-Espinosa \\ Universitat de Vic - Universitat Central de Catalunya \\ E-Mail: ruth.contreras@uvic.cat \\ Pedro Álvaro Pereira Correia \\ Universidade da Madeira \\ E-Mail: pacorreia@staff.uma.pt
}

\begin{abstract}
Both esports sponsors and academia are not aware of how disreputable behavior in the esports scene can negatively affect their brands. Hence, this research aimed at identifying which types of disreputable behavior in competitive gaming present the biggest threats to esports sponsors. In this quantitative and exploratory research, a nonprobability, purposive, and heterogeneous sampling method was employed to gather a sample of 1,592 esports fans who filled a closed-ended online survey. Results showed that illegal and unregulated gambling was a high-risk threat to esports sponsors; toxic behavior, match-fixing, and cheating were labeled as medium-risk threats; and sexism, cyberattacks, and doping were found to be low-risk threats. Besides being one of the first studies on esports sponsorships, which serves as a basis for future research in this market, the findings contribute to the sustainability of the esports industry and its sponsors. Managerial implications are also discussed.
\end{abstract}

Keywords: Esports, Sponsorship, Disreputable behavior, Marketing, Market analysis 


\section{INTRODUCTION}

According to Merriam-Webster (2016), disreputable behavior can be understood as dishonest, untrusted, or disrespectful practices or of a negative reputation. Similarly, Collin (2003) describes disreputable behavior as immoral or criminal acts. Examples of disreputable behavior in the field of sports include bribery, money-laundering, collusion, tax evasion, vote-rigging, match-fixing, referee bias, breach of contracts (Brooks, Aleem, \& Button, 2013), physical violence, threatening, foul language, abuse, and doping (Crompton, 1994). According to Cressey (1973), such practices usually stem from perceived pressure. Specifically, from stress, debt, perceived personal failure, or lack of recognition. Albrecht, Howe, and Rommey (1984) built on Cressey's work and added a desire for personal progression, fluid moral values, and desire to challenge or abuse.

Despite the wide variety of disreputable behavior, Crompton (2015) stresses that, although there are a large plethora of studies on the benefits of sponsoring sports, very little research has been conducted on the risks that these sports partnerships entail. This is concerning as, whenever a sponsorship is conducted, there is always the threat of some kind of disreputable behavior tainting the sponsor's brand image (Crompton, 1994) or causing severe financial hurdles (Crompton, 2015). Since these dishonorable acts may originate either from the event participants or from the spectators themselves, it is pretty hard to prevent them (Crompton, 1994). In fact, in his research, Crompton (2015) concluded that brands have little to no control over all forms of disreputable behavior that they may be associated with. According to Manoli (2018), this presents sponsors with a large number of risks and challenges. The author stresses that even if the brand had nothing to do with a particular scandal, they may be associated with it and thus negatively affected. In these situations, it is common for the fans' perceptions of the sponsors to worsen due to negative brand image transfer (Manoli, 2018).

Esports is another field that has recently started being plagued with disreputable behavior issues (Shabir, 2017; Ströh, 2017; Winnan, 2016). Winnan (2016) stated that anything that involves money, be it sports, esports, etc., will attract disreputable practices. Esports, also known as electronic sports or competitive gaming, take the form of video game tournaments (Ströh, 2017) where highly skilled gamers, commonly referred to as pro-players, participate (Shabir, 2017) to attain money, prestige, and prizes (Mooney, 2018). Like water sports, esports is a collective term covering a broad spectrum of video games and genres (Ströh, 2017). While, in low-tier competitions, players usually participate from their homes through an internet connection (Stein \& Scholz, 2016), high-tier tournaments take place in face-to-face settings like in large arenas filled with passionate crowds and are widely broadcasted through digital platforms (Gifford, 2017). 
Esports started gaining popularity in the early 2010s (Ströh, 2017). Since then, this market has been growing quite rapidly (Gainsbury, Abarbanel, \& Blaszczynski, 2017b; Keiper, Manning, Jenny, Olrich, \& Croft, 2017; Peša, Čičin-Šain, \& Blažević, 2017). With an annual growth rate of between 10\% (Mooney, 2018) and 40\% (Ströh, 2017), esports have been dubbed as, not only the world's fastest-growing sport (Kuhn, 2009; Sylvester \& Rennie, 2017), but also as one of the fastest-growing forms of digital entertainment (AEVI, 2018) and as one of the fastest-growing markets overall (Winnan, 2016). There has also been a steady (Shabir, 2017) and fast growth in viewership (Goetomo, 2017). In 2018, there were 395 million esports fans, and it is expected that there will be roughly 589 million by 2020 (Statista, 2019). On average, viewership has been increasing by $13.5 \%$ each year (Newzoo, 2018) and prize money increased by $350 \%$ between 2010 and 2013 (Brenda, 2017). Another attractive factor is that most esports fans have very high spending power (Li, 2016; Lieberman \& Esgate, 2002; Newzoo, 2016; Ströh, 2017). But, most important of all, the growth of this market is not slowing down (CGC Europe, 2015; Hiltscher \& Scholz, 2017; Sylvester \& Rennie, 2017), which means that the favorable statistics will continue to increase even further (Winnan, 2016) and new business opportunities will appear (Shabir, 2017). All of this success and popularity of esports is attracting several brands interested in sponsoring it (Shabir, 2017; Ströh, 2017; Winnan, 2016). However, although competitive gaming is a recent phenomenon, it already shares several of the same problems as in sport (Funk, Pizzo, \& Baker, 2018). One of the most challenging ones is the sponsors' susceptibility to various forms of disreputable behavior (Shabir, 2017; Ströh, 2017; Winnan, 2016).

Several brands have already had their image damaged due to sponsoring esports, and this was mainly because of the brands' unawareness of esports' problems with disreputable behavior (Winnan, 2016), which further accentuates the need for research that may inform them of such potential risks. These issues have even led some brands to terminate their esports sponsorships (Shabir, 2017). Considering that roughly 74\% of esports revenue comes from sponsors (Lokhman, Karashchuk, \& Kornilova, 2018) and that this industry cannot survive without them (Callus \& Potter, 2017; Holden, Kaburakis, \& Rodenberg, 2017; Winnan, 2016), the esports industry must identify all sources of dishonorable behavior and do its best to mitigate them (Ströh, 2017). As esports grow, disreputable behavior has become increasingly more apparent (Holden, Rodenberg, \& Kaburakis, 2017), and it is now a threat to the popularity, sustainability (Sylvester \& Rennie, 2017), and integrity of competitive gaming (Holden, Rodenberg, et al., 2017). Considering the elevated threat that disreputable behavior presents to sponsors, and in turn to the esports industry (Shabir, 2017; Ströh, 2017; Winnan, 2016), this research had the aim of exploring and identifying which concepts from the multidimensional threat of disreputable behavior (in the esports scene) have the biggest 
potential of harming esports sponsors. This research goal is further justified by the high lack of research on esports (Chalmet, 2015; Kozachuk, Foroughi, \& Freeman, 2016) and its sponsorships (Korpimies, 2017; Ströh, 2017). The remainder of the paper unfolds as follows. A literature review is presented on the most prevalent types of disreputable behavior in esports, and examples of such acts in this field are provided whenever possible. The review gives rise to seven hypotheses and a conceptual model, which are then submitted to empirical scrutiny. For this, a methodological path is delimited, exposing the detailed steps taken to conduct the empirical research. Afterward, the results section exposes the collected data, which the following chapter, discussion, critically analyses. The conclusions link the entire research and present an empirical model of the most threatening forms of disreputable behavior for esports sponsors. Limitations and future research are subsequently presented.

\section{THEORETICAL BACKGROUND AND HYPOTHESES DEVELOPMENT}

\section{Toxic Behavior}

Esports have been suffering from toxic behaviors to such an extent that it has already become quite common during offline tournaments (Blackburn \& Kwak, 2014). These negative interactions are promoted by the extreme competitiveness of the scene, by the high dependence on teamwork (Neto, Yokoyama, \& Becker, 2017), and by the anonymous nature of the internet, which facilitates hostility and aggressiveness (Blackburn \& Kwak, 2014). According to Neto et al. (2017), as video games' competitive nature increases, so does the probability of them inciting toxicity. Likewise, when low performance is accompanied by exalted stress, toxicity will emerge. More importantly, toxicity can quickly spread. The authors state that even non-toxic players can easily become angry and frustrated when exposed to it. Direct contact with toxic behavior will give rise to insults, blaming, and even break team communications. This will lead both players and viewers to have bad experiences, decrease player and viewer retention, and tarnish the video game's reputation (Neto et al., 2017).

Esports fans do not like toxic players, but toxicity has become customary among several regular gamers $(\mathrm{Li}, 2016)$ to such an extent that one-fourth of the calls to game developers' customer support centers are of people complaining about toxic gamers (Blackburn \& Kwak, 2014). Even so, Li (2016) mentions that when the pro-players themselves are toxic, the community's reaction is much more severe. Several instances where pro-players used offensive language led to large internet backlashes. The author provides two examples. The first happened when Jake "orb" Sklarew called his adversaries derogatory names, leading various fans to organize a campaign and complain to his sponsors. The second occurred when Greg "IdrA" Fields disrespected both his adversaries and the community itself, which led to another wave of complaints 
to his sponsors. As a result, both of these pro-players were fired (Li, 2016). Because of this, and other similar occurrences, toxicity is now a threat to the video game industry (Blackburn \& Kwak, 2014) and all its stakeholders (Neto et al., 2017). Thus, we hypothesize the following:

$\mathbf{H}_{1}$ : Toxic behavior in the esports scene is a threat for esports sponsors.

\section{Sexism}

Unlike the general video game statistics, where the percentage of female players (i.e., 41\%) is almost equal to male's (ESA, 2017), the esports scene has largely been filled by male pro-players (CGC Europe, 2015; Funk et al., 2018; Mooney, 2018; Winnan, 2016). Statistics show that only $8 \%$ of esports players are female (CGC Europe, 2015; Winnan, 2016) and that roughly just $10 \%$ of the esports audience is female (Billings, Rodgers, Rodgers, \& Wiggins, 2019; Zolides, 2015). Furthermore, only two females are among the top 200 highest earning esports players (SuperData, 2015). It is believed that this is because female pro-players have to overcome more challenges to reach the top than males (Zolides, 2015). Even if they are as good as male pro-players (Misra \& Danwani, 2012), they are still underestimated (Kaye, Pennington, \& McCann, 2018; Menti \& Araújo, 2017) and seen as worthless (Misra \& Danwani, 2012). It is even common for them to be excluded from teams or by tournament organizers simply because of their gender (Menti \& Araújo, 2017).

Women in esports have to endure several issues, like discrimination, gender inequality (Winnan, 2016), sexualization, abusive (Cunningham et al., 2018) or offensive language (Menti \& Araújo, 2017), heckling, and harassment (Mooney, 2018). Menti and Araújo (2017) present a report from a female pro-player who states that women are devalued and that there are macho attitudes and prejudice against them. One study was even able to detect comments containing misogyny and direct death and rape threats towards women in esports (Menti \& Araújo, 2017). For example, Kelly "kellyMILKIES" Ong received modified pictures with her face in nude bodies or being raped or killed ( $\mathrm{Li}, 2016)$. The brutal, asinine, and threatening comments and acts have led several female pro-players to quit (Winnan, 2016). Regrettably, these issues have become commonplace in esports (Cunningham et al., 2018), so much so that even some esports fans defend that these actions against women are a natural element of esports (Winnan, 2016). Menti and Araújo (2017) defend that, although sexism is common, people must understand that, unlike women, men are not cursed due to their gender. On the other hand, the authors stress that it is common for female players to hear things like: "Go wash the dishes" (p. 81) or "Send nudes" (p. 83), but men never hear things like "Go change a tire" (p. 83). Unfortunately, there is not a procedure for female players 
to report these abuses (Menti \& Araújo, 2017). This is quite concerning, especially because what all these females want is to play the video games they love and to participate in esports (Misra \& Danwani, 2012).

The still present gender roles of society, which dictate that women must be feminine, docile, submissive, and inferior to men, coupled with the high percentage of males in esports, present large barriers to the entry of females into esports (Menti \& Araújo, 2017). According to Winnan (2016), this makes esports very unwelcoming for women, and although some efforts have been made to mitigate several of esports' issues, gender inequality has been largely ignored. This is a missed opportunity as the attraction of more women to esports has the potential to help catapult esports' popularity and bring it closer to the mainstream (Winnan, 2016). Furthermore, these issues of harassment, discrimination, and sexism are a threat to the sponsors' image because negative publicity can easily spread and harm their reputation, which may lead potential sponsors to avoid esports and existing ones to terminate their sponsorships (Ströh, 2017). Therefore, we propose the following hypothesis:

$\mathbf{H}_{2}$ : Sexism in the esports scene is a threat for esports sponsors.

\section{Illegal and Unregulated Gambling}

All competitions with large numbers of engaged fans are likely to lead people to wager on its outcomes (Winnan, 2016), and the same is now happening in esports (Mooney, 2018). However, Gainsbury, Abarbanel, and Blaszczynski (2017a) mention that the infancy of esports and the doubts about this industry's legitimacy have led licensed gambling websites to offer a very limited variety of betting options and only allow small bets to be placed. This, in turn, led people to use non-regulated and offshore wagering websites that provide improved and more varied gambling experiences (Gainsbury et al., 2017a). As a result, illegal esports gambling has become so popular that in 2016 it generated $\$ 7.4$ billion (Shabir, 2017; Ströh, 2017), a value much larger than the $\$ 4$ billion that compose the licensed sports betting of Last Vegas (Holden, Rodenberg, et al., 2017).

However, the main concern here is the use of skins (i.e., in-game cosmetic items), which are used for gambling purposes (Holden \& Ehrlich, 2017). Skin gambling is in a legal grey area (Martinelli, 2017; Ströh, 2017). As reported by Holden and Ehrlich (2017), this is because, although they can be bought with real-world money, in the government's eyes, they are not seen as items of value. Thus, federal courts have refused to apply any laws on the transaction of these virtual items (Holden \& Ehrlich, 2017). This also means that it is impossible to label skin wagering as an illegal activity (Holden, 
2017). Because skin gambling is not classified as gambling, it cannot be subjected to regulation (Martinelli, 2017).

The use of skins for gambling purposes has caused several problems in the esports industry (Sylvester \& Rennie, 2017), especially because they allow almost anyone to bypass all kinds of betting restrictions (Mooney, 2018). For example, skin gambling makes it very easy for underage fans to indirectly bet with money (Shabir, 2017; Sylvester \& Rennie, 2017; Winnan, 2016). Furthermore, the illegal gambling websites themselves do not regulate their user-base (Sylvester \& Rennie, 2017). They do not analyze if people are betting from countries or states that have legalized gambling or if the bettor is old enough to gamble (Mooney, 2018). All of this has turned underage skin gambling into a severe issue (Griffiths, 2017; Winnan, 2016). Several children have been caught stealing their parents' credit cards to wager (Griffiths, 2017; Shabir, 2017; Winnan, 2016). Some have even spent thousands of dollars (Shabir, 2017). Regrettably, it does not seem like this issue will disappear any time soon (Griffiths, 2017).

As esports grow, so does underage wagering. This is turning into a major concern and putting the well-being of esports at risk (Shabir, 2017). Skin gambling is now the dominating form of wagering in esports (Gainsbury et al., 2017a) and has helped popularize esports gambling (Griffiths, 2017). In fact, although it is not very well known among the mainstream, the truth is that skins are now amongst the most popular virtual currencies in the world (Holden, 2017). This high popularity of esports wagering (Griffiths, 2017) and the existence of underage gambling has attracted a lot of negative press (Holden \& Ehrlich, 2017) and unfavorable word of mouth, with some stating that esports is an unregulated industry where even children can wager (Griffiths, 2017). All the negative attention and controversies (Martinelli, 2017) mean that skins (Sylvester $\&$ Rennie, 2017) and illegal gambling are a threat to esports (Gainsbury et al., 2017b; Ströh, 2017). These gambling scandals greatly damage esports' image (Mah, 2011) and limit their commercial opportunities (Sylvester \& Rennie, 2017). Thus, we propose that,

$\mathbf{H}_{3}$ : Illegal and unregulated gambling in the esports scene is a threat for esports sponsors.

\section{Match-Fixing}

The illegal act of match-fixing has also invaded esports (Mah, 2011; Winnan, 2016). According to $\mathrm{Li}$ (2016), this is a strong temptation for pro-players. If they bet against themselves and purposefully lose, they will reap considerable profits. The author stresses that pro-players with unstable salaries or tournament wins are very prone to do this because, while a player that does match-fixing is sure to win some money, one who just tries to win the tournament's prize money cannot be sure he will win 
anything. Furthermore, there are instances where match-fixing will provide much higher profits than the tournament's top prize money (Li, 2016).

These illegal acts have caused several scandals (Ströh, 2017; Winnan, 2016). Ströh (2017) provides two of the most striking examples. One happened when Cheon Min$\mathrm{Ki}$, a 17-year-old esports player, attempted suicide because his manager ordered his team to lose a match on purpose. Another scandal resulted in several pro-players being arrested in South Korea (Ströh, 2017), including a tier 1 player named Ma "sAviOr" Jae Yoon, because they were involved in a match-fixing ring. As a result, their championship titles were taken ( $\mathrm{Li}, 2016)$, they were permanently banned from all future esports events by the Sanction Subcommittee of the Korea e-Sports Association (KeSPA), and they were also charged in criminal courts (Winnan, 2016). Here, Yoon was sentenced to 120 hours of community service and two years of probation (Li, 2016), and several players, staff, and proprietors of 12 illegal wagering websites were also charged (Winnan, 2016). Another match-fixing incident resulted in Valve banning a team sponsored by iBUYPOWER (Li, 2016). As esports grow, it may even attract the attention of organized crime (Ströh, 2017).

These, and several other incidents, have shocked the esports community (Li, 2016), either damaging (Ströh, 2017; Winnan, 2016) or leading to the closure of some tournaments (Brickell, 2017) or to the termination of several sponsorships (Winnan, 2016). Despite match-fixers being arrested and prosecuted, these scandals still severely damage the integrity of esports and put the entire scene under suspicion (Li, 2016), and may lead valuable stakeholders to avoid esports (Brickell, 2017). Thus,

$\mathbf{H}_{4}$ : Match-fixing in the esports scene is a threat for esports sponsors.

\section{Cheating and Cyber-Attacks}

Like with any other sport (Winnan, 2016), esports is not free of cheating (Mooney, 2018). In fact, there have been several cheating incidents in competitive gaming (Winnan, 2016). There are numerous ways of cheating. Some use software to manipulate the video games' code (Mooney, 2018; Ströh, 2017), providing them with aimbots, enhanced visibility (Ströh, 2017), infinite ammo and health (Winnan, 2016), and other unfair abilities that no one else can use (Mooney, 2018). Others exploit existing in-game glitches or use macros (Ströh, 2017). Some even manipulate the video game's files or modify the gaming hardware (Winnan, 2016).

As Winnan (2016) reported, one of the biggest cheating scandals in esports happened during the 2014's CS: $G O$ finals at DreamHack. According to the author, teams Titan and Epsilon had just been disqualified for cheating and, during the finals, Fnatic used a glitch that allowed them to see and shoot almost everyone on the map, 
which gave them the victory. However, after being accused of cheating, they did not plead guilty. Instead, they accused their adversaries of exploiting another bug. Ultimately, the tournament organizers decided to repeat the finals. But this created a lot of controversies and led the very vocal fans to inundate various social networks with angry comments towards Fnatic, which forced the team to forfeit the tournament (Winnan, 2016).

Shabir (2017) mentions that cheating in esports can also be done through cyberattacks. For instance, Distributed Denial of Service (DDoS) attacks aim to artificially slow down the opponents' internet speed or even completely freeze it. This allows disabling the opponent, which results in them being vulnerable for some time and heavily influences the outcome of online matches (Shabir, 2017). While some use this to win tournament prize money, others use it to capitalize from the betting market (Ströh, 2017).

Although it is somewhat easy to identify cheaters in esports since the games run on computers, which means that all the gameplay data is stored and traceable (Winnan, 2016), these behaviors are still quite common (Shabir, 2017; Ströh, 2017). Cheating is a threat to the legitimacy of esports (Shabir, 2017). It is illegal (Christophers, 2011), provides an unfair advantage, damages the experience, reputation, and integrity of esports (Ströh, 2017), and discredits the competitive gaming scene (Winnan, 2016). More importantly, it can lead to a decrease in the number of viewers and the number of commercial partners because it is also a threat for all of them (Ströh, 2017). Hence, we propose the following hypotheses:

$\mathbf{H}_{5}$ : Cheating in the esports scene is a threat for esports sponsors.

H6: Cyberattacks in the esports scene are a threat for esports sponsors.

\section{Doping}

Although doping is a form of cheating, it is presented in a separate subchapter due to the number of issues it has caused and its health implications. Despite not being a physical sport, doping has become commonplace in esports (Mooney, 2018; Ströh, 2017). Competitive gaming requires fast decision-making and reflexes (Ströh, 2017). All it takes is for a single pro-player to underperform for the entire team to lose (Winnan, 2016). This factor, coupled with the high prize pools of some tournaments (Stivers, 2017), has made psychostimulants like Vyvanse, Ritalin, and Adderall, enhancing awareness and reaction times alluring to pro-players (Ströh, 2017; Winnan, 2016). However, doping is illegal (Stivers, 2017) and is starting to threaten the esports scene (Mooney, 2018; Ströh, 2017). 
According to Holden, Kaburakis, and Rodenberg (2018), the types of drugs being used do not include just non-prescription and prescription stimulants. It also includes powerful gaming elixirs that are sold over the internet. These dangerous cocktails may lead to various health hazards, like concussions (Holden et al., 2018). Furthermore, these drugs are not miracle pills that can turn everyone into pro-players (Winnan, 2016). In fact, Mooney (2018) states that there is very poor scientific evidence supporting any of their supposed benefits. By contrast, there is clear scientific evidence pointing to the health dangers of these stimulants (Mooney, 2018), some of which are only supposed to be taken by individuals with attention-deficit/hyperactivity disorders (ADHD; (Winnan, 2016). The misuse of these stimulants without any kind of medical prescription can be quite harmful and lead to addiction, anxiety, elevated heart rate and blood pressure (Mooney, 2018), accelerated weight loss, and serotonin syndrome (Winnan, 2016).

The topic of doping in esports gained a lot of attention in 2015 when the pro-player, Kory "Semphis" Friesen, declared that he and his entire team had been making use of psychostimulants (Stivers, 2017; Winnan, 2016) and that this was a common practice among all esports pro-players (Winnan, 2016). This generated a lot of negative press and concerns about the safety and integrity of esports (Ströh, 2017; Winnan, 2016). Because of these scandals, doping in esports has become a very serious concern (Holden et al., 2018). Besides presenting several health risks (Mooney, 2018), they can also damage esports' image (Ströh, 2017) and integrity (Holden et al., 2018), and create numerous economic challenges (Ströh, 2017). If a scientific study proves that esports is influencing most gamers to consume performance-enhancing drugs, or if esports players start dying with overdoses, this industry will greatly suffer (Winnan, 2016). Thus,

$\mathbf{H}_{7}$ : Doping in the esports scene is a threat for esports sponsors.

\section{Conclusion}

This research focused on analyzing the most widely mentioned types of disreputable behavior that present significant threats to esports sponsors. In total, it was possible to verify that seven types of disreputable behavior in esports are being much more talked about than others, which leads to the belief that these are the most problematic ones. Figure 1 provides a conceptual model of the literature's most prominent types of disreputable behavior. 


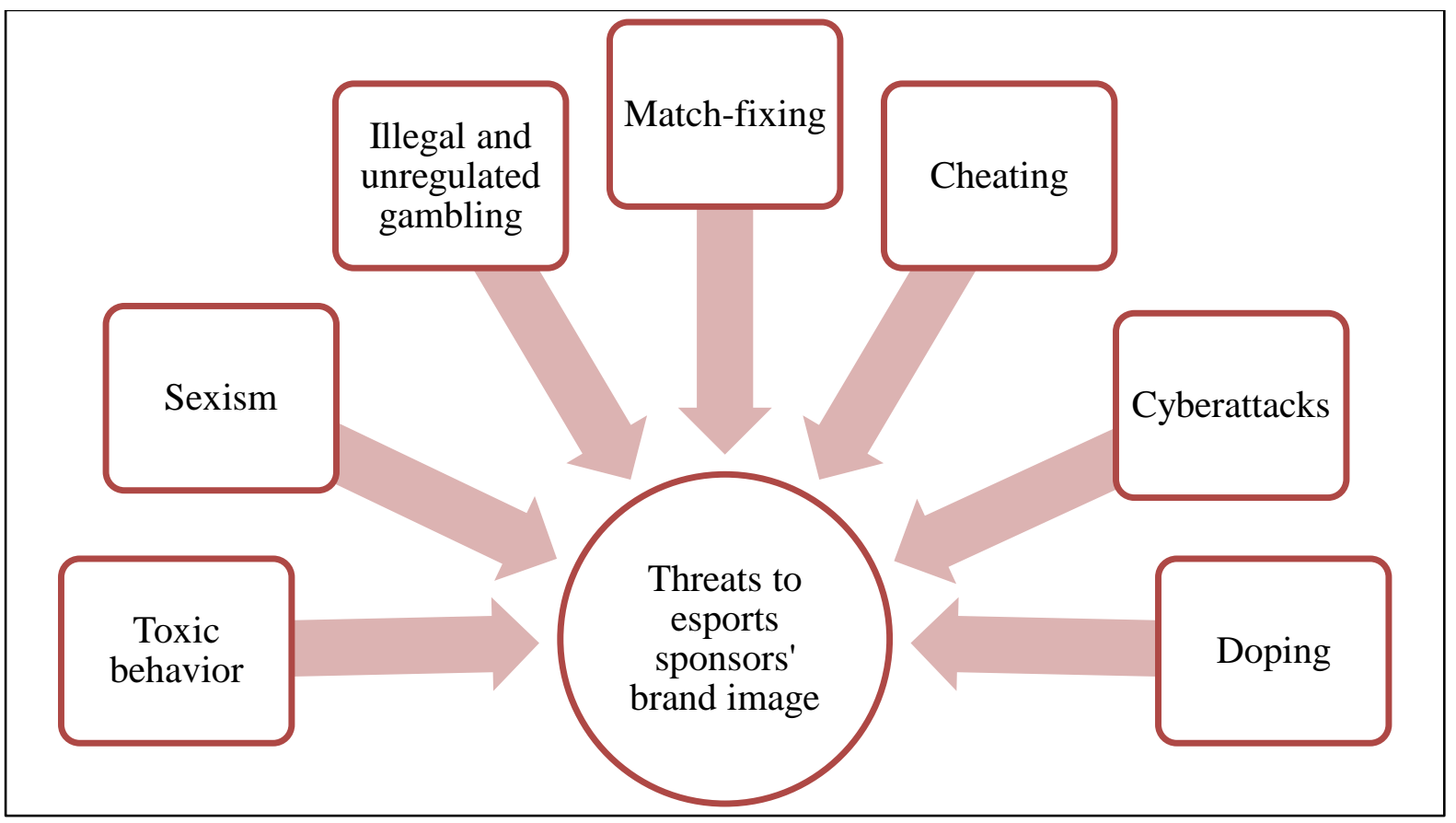

Figure 1 Most Threatening Forms of Disreputable Behavior for Esports Sponsors (Conceptual Model)

\section{METHODOLOGY}

The accentuated scarcity of scientific research on esports sponsorships (Korpimies, 2017; Ströh, 2017) and the industry's rapid evolution (Scholz, 2019) implies that the previously presented conceptual model may not be accurate and updated. Furthermore, in the literature, it is not mentioned which types of disreputable behavior present the biggest threats to sponsors, which is reflected in the conceptual model. The lack of research on esports sponsorships also means that the model is very superficial and does not indicate the main subtypes of disreputable behavior that make these items a threat to the esports sponsors' image. Simply put, it is impossible to reach the research goal with such limited literature. As such, it was necessary to gather higher-quality empirical data. This allowed the development of an empirical model, which highly improved the detail, reliability, significance, and overall quality of the conceptual model. To develop the empirical model, an exploratory and quantitative research method was used. Alongside this, a cross-sectional time horizon was employed, with the researchers taking an overt stance in a non-contrived research setting.

\section{Population and Sampling}

The study sample consisted of esports fans $(n=1,592)$ who were subjected to a non-probabilistic purposive heterogeneous sampling. That is, there was a purposeful selection of a diverse group of esports fans. This was done to ensure that the sample encapsulated the largest possible spectrum of esports fans. To achieve this, a database 
of the most popular esports video games was first created. This was done by identifying the most-viewed esports video games of 2019 (from January to July) and the esports video games with the cumulative highest prize money awarded. The data on the monthly most-viewed esports video games were gathered from Newzoo (2020), a website that presents a monthly updated list of the ten most-watched esports games from YouTube and Twitch. Newzoo is a popular online platform for esports-related statistics that is extensively used by various authors and researchers like Jenny et al. (2018), Shabir (2017), Ströh (2017), Sylvester and Rennie (2017), etc. The data from the esports games with the highest prize money awarded was retrieved from Esports Earnings (2020), an online platform that, among other things, presents the 100 esports games with the most prize money awarded. This website is extensively used by numerous researchers, including Cunningham et al. (2018), Menasce (2019), Ströh (2017), Owens (2016), etc. Table 1 presents a list of the most popular esports titles by combining the 100 esports games with the highest prize money awarded and the ten most-viewed esports games from January to July 2019. This list was used as a guide to select esports-related forums focused on at least one of the games from Table 1. In the selected forums, a request for participation and a link to the online survey were placed. Besides these, requests were also placed on more general esports forums, including forums focused on popular proplayers and teams, or popular esports tournaments. Table 2 shows the sample's demographics.

Table 1 Most-Watched and Highest Prize Money Awarded Esports Games

\begin{tabular}{ll}
\hline CrossFire & Call of Duty: Infinite Warfare \\
H1Z1 & Guild Wars 2 \\
Madden NFL 2013 & FIFA 19 \\
Super Smash Bros. Brawl & Project Gotham Racing 3 \\
Halo: Reach & SMITE \\
Paladins & Call of Duty: Black Ops III \\
StarCraft II & League of Legends \\
Magic: The Gathering Online & Call of Duty $4:$ Modern Warfare \\
Super Smash Bros. Melee & PLAYERUNKNOWN'S BATTLEGOUNDS \\
Call of Duty: Black Ops 2 & Super Smash Bros. for Wii U \\
Magic: The Gathering Arena & Super Street Fighter IV Arcade Edition \\
Counter-Strike: Source & StarCraft: Brood War \\
FIFA Online 4 & Madden NFL 2018 \\
Heroes of Newerth & Street Fighter V \\
Shadowverse & Counter-Strike: Global Offensive \\
World of WarCraft & Gwent \\
NBA 2 K18 & Call of Duty: Modern Warfare 3 \\
FIFA 18 & Call of Duty: World War II \\
\hline
\end{tabular}




\begin{tabular}{|c|c|}
\hline Painkiller & Overwatch \\
\hline Forza Motorsport 7 & Super Smash Bros. Ultimate \\
\hline Age of Empires II: The Age of Kings & Blade \& Soul \\
\hline Teamfight Tactics & Ultra Street Fighter IV \\
\hline WarCraft III & Halo: Combat Evolved \\
\hline Quake Champions & Call of Duty: Ghosts \\
\hline Defense of the Ancients & iRacing.com \\
\hline Old School Runescape & Call of Duty: Advanced Warfare \\
\hline FIFA 13 & Injustice 2 \\
\hline Gears of War 4 & Street Fighter V: Arcade Edition \\
\hline Tom Clancy's Rainbow Six: Siege & Arena of Valor \\
\hline Quake Live & Gears of War \\
\hline Quake 4 & FIFA Online 3 \\
\hline Counter-Strike & Call of Duty: Black Ops \\
\hline Call of Duty: Black Ops 4 & Team Fortress 2 \\
\hline Dota 2 & Realm Royale \\
\hline Doom 3 & Heroes of the Storm \\
\hline Brawlhalla & Pro Evolution Soccer 2017 \\
\hline Halo 4 & Halo 2 Anniversary \\
\hline World in Conflict & Apex Legends \\
\hline World of Tanks & Point Blank \\
\hline PLAYERUNKNOWN'S BATTLEGROUNDS & Vainglory \\
\hline \multicolumn{2}{|c|}{ Mobile } \\
\hline Quake III Arena & Dead or Alive 4 \\
\hline ShootMania Storm & FIFA 17 \\
\hline Turbo Racing League & Attack on Titan Tribute Game \\
\hline Fortnite & Halo 3 \\
\hline Clash Royale & Mortal Kombat X \\
\hline Tekken 7 & rFactor 2 \\
\hline Halo 5: Guardians & Counter-Strike Online \\
\hline Rocket League & Battlefield 4 \\
\hline KartRider & Madden NFL 2017 \\
\hline Halo 2 & Hearthstone \\
\hline
\end{tabular}

Note: Table based on Esports Earnings (2020) and Newzoo (2020).

Table 2 Esports Fans' Demographics

\begin{tabular}{lrrrrrr}
\hline & \multicolumn{2}{c}{$n=1,592$} & & & & \\
\cline { 2 - 5 } & Valid & No answer & Valid \% & Mean & SD & Mode \\
\hline Gender & 1,569 & 23 & & & & \\
Female & 130 & & 8.3 & & & \\
$\quad$ Male & 1,439 & & 91.7 & & & \\
Age & 1,495 & 97 & & 23.8 & 6. & 18 \\
& & & & & & 8
\end{tabular}




\begin{tabular}{|c|c|c|c|}
\hline Marital status & 1,545 & 47 & \\
\hline Single & 1,130 & & 73.1 \\
\hline Cohabiting & 248 & & 16.1 \\
\hline Married & 147 & & 9.5 \\
\hline Divorced & 15 & & 1 \\
\hline Widowed & 5 & & .3 \\
\hline Education & 1,541 & 51 & \\
\hline $6^{\text {th }}$ grade or less & 3 & & .2 \\
\hline $7^{\text {th }}$ to $12^{\text {th }}$ grade & 606 & & 39.3 \\
\hline Bachelor degree & 674 & & 43.7 \\
\hline Master degree & 123 & & 8 \\
\hline $\mathrm{PhD}$ & 25 & & 1.6 \\
\hline Post-doctorate & 8 & & .5 \\
\hline Other & 102 & & 6.6 \\
\hline Employment status & 1,548 & 44 & \\
\hline Student & 695 & & 44.9 \\
\hline Employed & 679 & & 43.9 \\
\hline Homemaker & 16 & & 1 \\
\hline Unemployed & 110 & & 7.1 \\
\hline Retired & 10 & & .6 \\
\hline Other & 38 & & 2.5 \\
\hline Region & 1,561 & 31 & \\
\hline Africa & 10 & & .6 \\
\hline Asia & 45 & & 2.9 \\
\hline Europe & 492 & & 31.5 \\
\hline North America & 936 & & 60 \\
\hline Oceania & 47 & & 3 \\
\hline South America & 31 & & 2 \\
\hline Ethnicity & 1,527 & 65 & \\
\hline American Indian or Alaska Native & 21 & & 1.4 \\
\hline Asian & 184 & & 12 \\
\hline Black or African American & 53 & & 3.5 \\
\hline $\begin{array}{l}\text { Hispanic, Latino, or Spanish } \\
\quad \text { origin }\end{array}$ & 114 & & 7.5 \\
\hline Middle Eastern or North African & 27 & & 1.8 \\
\hline $\begin{array}{l}\text { Native Hawaiian or other Pacific } \\
\text { Islander }\end{array}$ & 18 & & 1.2 \\
\hline White & 1,221 & & 80 \\
\hline Other & 63 & & 4.1 \\
\hline
\end{tabular}

Note. $n=$ Sample size, $\mathrm{SD}=$ Standard deviation. For ethnicity, participants were able to select more than one option. 
The sample's demographic data is in line with the literature. According to SuperData (2015), 87\% of esports fans are male, Zolides (2015) states that $90 \%$ are male, and Billings et al. (2019) defend that $92.4 \%$ are male. This is close to the sample's ratio of $91.7 \%$ males and $8.3 \%$ females. According to Mooney (2018), half of the esports fans are aged between 18 and 25, and, according to Nielsen Esports (2017), the average esports fan is 26 years old. This is close to the sample's mean of 23.8. The remaining demographic data is not widely covered in the literature, so a comparison was not made.

\section{Data Collection Tool, Application Method, and Data Analysis}

A closed-ended questionnaire was developed for this research and applied in the form of an online survey (only the question regarding the participant's age was openended). The survey was closed-ended so that a large number of esports fans could be analyzed. The closed-ended questions were composed of multiple-choice, dichotomous and checklist questions and a rating scale. The latter was a five-point frequency rating scale (i.e., never, rarely, occasionally, frequently, and always). Both the questions and answer options were based on the main findings from the literature review. For each type of disreputable behavior, in general, participants were asked how often they tend to observe instances of that particular behavior (via a frequency rating scale). Suppose that led them to dislike the sponsored entity that showed that behavior (via a dichotomous "Yes" or "No" question), which types of that specific behavior made them dislike the sponsored entity (via a checklist question), and if that led them to dislike the sponsors of those entities (via a dichotomous "Yes" or "No" question). Multiple-choice questions were used on rare occasions (e.g., to verify who tends to be more sexist: "men," "women," "both," or "none").

The questionnaire was developed on the online survey platform Google Forms, which is recommended by various authors, including Cohen, Manion, and Morrison (2018). Since the data collection tool is an online survey, it was applied through selfrecruitment and self-administration. In the online forums, a request for participation was placed, and a link was provided that redirected participants to the online survey webpage. To ensure that only esports fans filled out the survey, a contingency question was placed at the start of the questionnaire asking if the participant regularly watched or participated in competitive gaming. Those who responded "No" were not able to fill out the remainder of the survey and were excluded from the sample. Before the empirical data collection, the survey was pretested on 41 esports fans and three individuals with scientific research experience. The answers from this pretest phase were not used in the empirical data analysis. The data collection started on 5 August 2019 and ended on 24 August 2019 (i.e., 20 days). Requests for participation were 
placed in 203 different esports-related sub-forums of the Reddit website and on 81 esports-related Discord Channels (each request was placed only once on each subforum). Lee (2017) stated that Discord and Reddit are the most used social platforms by the gaming community. Since the data is quantitative, it was analyzed with IBM SPSS Statistics 25. The analysis procedure was comprised of univariate frequency distributions (only participant age was analyzed via univariate central tendency).

\section{RESULTS AND DISCUSSION}

\section{Toxic Behavior}

As Figure 2 indicates, most esports fans occasionally or rarely see pro-players, teams, or tournaments engaging in toxic behaviors. The figure also shows that almost every fan (i.e., $95.9 \%$ or $1,527 / 1,592$ ) has seen at least some form of toxic behavior in esports. In Table 3, it is shown that, from this group, the majority mentioned to have started disliking a pro-player, team, or tournament because they showed some type of toxic behavior. The types of toxic behavior that led most people to dislike an esports entity were: encouraging self-harm, racism, homophobia, and showing physical signs of aggressiveness and hostility. Other less mentioned types of disreputable behavior included direct physical aggression as well as swearing and cursing. Still from the same group, although the large majority stated not to dislike the brands that sponsored these toxic pro-players, teams, or tournaments, there was still a significant percentage of fans who disliked these brands.

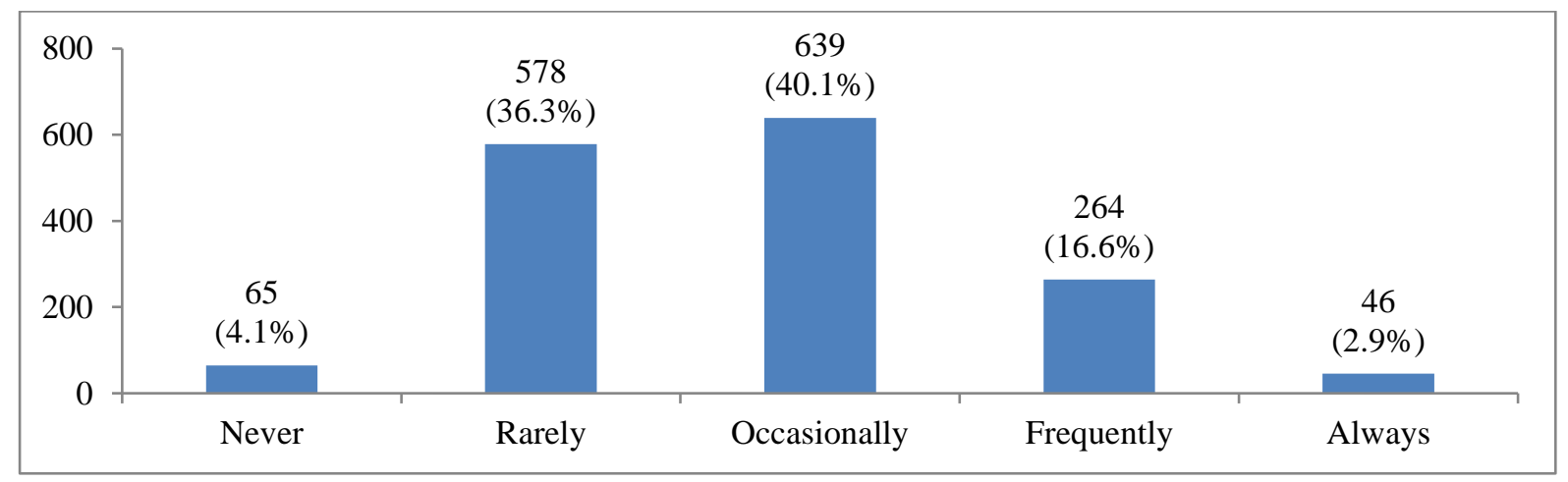

Figure 2 Fans' Frequency of Seeing Toxic Behaviors in Esports 
Table 3 Toxic behavior

\begin{tabular}{|c|c|c|c|}
\hline $\begin{array}{l}\text { Question } \\
\text { Answer option }\end{array}$ & $\begin{array}{r}n= \\
1,527\end{array}$ & $\begin{array}{r}n= \\
1,031\end{array}$ & $\begin{array}{r}\text { Valid } \\
\% \\
\end{array}$ \\
\hline \multicolumn{4}{|l|}{$\begin{array}{l}\text { Have you ever started disliking a pro-player, team, or } \\
\text { tournament because they were toxic? }\end{array}$} \\
\hline Yes & 1,031 & & 67.5 \\
\hline No & 496 & & 32.5 \\
\hline \multicolumn{4}{|l|}{$\begin{array}{l}\text { What types of toxic behaviors made you dislike them? Select } \\
\text { all that apply. }\end{array}$} \\
\hline Direct physical aggression & & 314 & 30.5 \\
\hline $\begin{array}{l}\text { Showing physical signs of aggressiveness and hostility } \\
\text { (but not attempting to physically harm) }\end{array}$ & & 467 & 45.3 \\
\hline Swearing & & 260 & 25.2 \\
\hline Racism & & 634 & 61.5 \\
\hline Homophobia & & 557 & 54 \\
\hline $\begin{array}{l}\text { Encouraging suicide, telling people to "get cancer", die, } \\
\text { or similar }\end{array}$ & & 637 & 61.8 \\
\hline Other & & 184 & 17.8 \\
\hline \multicolumn{4}{|l|}{$\begin{array}{l}\text { Did you start disliking their sponsors because they were } \\
\text { supporting toxic pro-players, teams, or tournaments? }\end{array}$} \\
\hline Yes & & 294 & 28.5 \\
\hline No & & 737 & 71.5 \\
\hline
\end{tabular}

The results supported $\mathrm{H}_{1}$ that toxic behavior is a threat for esports sponsors. Specifically, toxic behavior was labeled as a medium-risk threat for esports sponsors since the large majority referred to have seen some form of it in esports and to dislike the pro-players, teams, or tournaments connected to these acts. Yet, most fans reported that they do not dislike the brands that sponsor entities connected to toxicity.

Several points of the empirical data are in line with the literature. The fact that almost every esports fan indicated to have seen some form of toxic behavior in the professional esports scene is in line with Blackburn and Kwak (2014), and Li (2016) statements that toxic behaviors have become quite common in esports. Likewise, the data showed that most esports fans have started disliking a pro-player, team, or tournament that exhibited toxic behaviors. This is in sync with $\mathrm{Li}$ (2016), who mentions that esports fans do not like toxic players. It was also possible to see that the large majority of fans did not develop negative feelings towards the brands that sponsored the aforementioned toxic entities. This makes sense if we bear in mind that Li (2016) referred that several esports fans simply reported some pro-players' toxic behaviors to their sponsors. The author never mentions that these sponsors suffered from any sort of backlash from the esports fans, just the toxic pro-players. 
Nevertheless, it is important to note that the still significant percentage of fans who mentioned that they started disliking the sponsors of toxic esports entities and the issues of subconscious negative brand image transfer make this and other types of disreputable behavior a threat for esports sponsors. The fact that $95.9 \%$ of fans have seen toxicity in esports and roughly one-fourth of the sample showed negative feelings towards sponsors of toxic entities implies that sponsors must carefully monitor all actions of the sponsored party and quickly terminate partnerships if toxicity is verified as well as issue a public statement reporting that the brand does not condone such behaviors.

\section{Sexism}

According to Figure 3, most esports fans have rarely or occasionally seen proplayers, teams, or tournaments being sexist. In the figure, it is also shown that the large majority of esports fans (i.e., $81.8 \%$ or 1,302/1,592) have seen some form of sexist behavior in esports. As shown in Table 4, most fans indicated to see male pro-players most often being sexist from this group. A slight majority also reported that they have not started disliking a pro-player, team, or tournament that showed signs of sexism. Still, a significant percentage started disliking these sexist entities. From this latter group, the types of sexist behavior that made them dislike these entities the most were: undermining or devaluing, harassing, disrespecting, sexualizing, and threatening. A less mentioned type of sexist behavior was excluding female pro-players from tournaments or teams. Furthermore, almost half of esports fans started disliking the brands sponsoring sexist pro-players, teams, or tournaments.

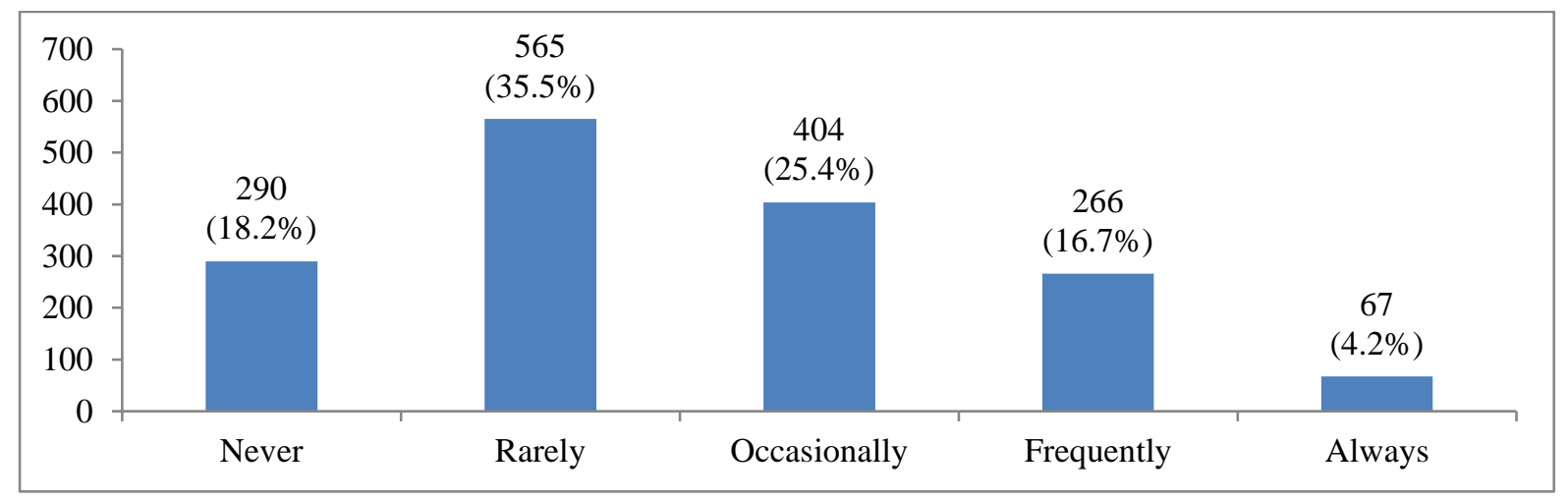

Figure 3 Fans' Frequency of Seeing Sexism in Esports 
Table 4 Sexism

\begin{tabular}{|c|c|c|c|c|}
\hline $\begin{array}{l}\text { Question } \\
\quad \text { Answer option }\end{array}$ & $\begin{array}{c}n= \\
1,592\end{array}$ & $\begin{array}{c}n= \\
1,302\end{array}$ & $n=559$ & $\begin{array}{l}\text { Valid } \\
\%\end{array}$ \\
\hline \multicolumn{5}{|l|}{ Is there a lack of female pro-players in esports? } \\
\hline No & 364 & & & 22.9 \\
\hline Yes, a small lack & 210 & & & 13.2 \\
\hline Yes, a moderate lack & 395 & & & 24.8 \\
\hline Yes, a high lack & 623 & & & 39.1 \\
\hline \multicolumn{5}{|l|}{ Whom do you see most often being sexist? } \\
\hline Men & & 899 & & 69 \\
\hline Women & & 56 & & 4.3 \\
\hline Both at the same degree & & 347 & & 26.7 \\
\hline \multicolumn{5}{|l|}{$\begin{array}{c}\text { Have you ever started disliking a pro-player, team, } \\
\text { or tournament because they were sexist? }\end{array}$} \\
\hline Yes & & 559 & & 42.9 \\
\hline No & & 743 & & 57.1 \\
\hline \multicolumn{5}{|l|}{$\begin{array}{l}\text { What types of sexist behaviors made you dislike } \\
\text { them? Select all that apply. }\end{array}$} \\
\hline Excluding females from tournaments or teams & & & 170 & 30.4 \\
\hline $\begin{array}{l}\text { Harassment (e.g., continuously disturb, torment, } \\
\text { pester, etc.) }\end{array}$ & & & 430 & 76.9 \\
\hline Threatening (e.g., death or rape threats) & & & 248 & 44.4 \\
\hline Undermining or devaluing & & & 437 & 78.2 \\
\hline Disrespecting & & & 424 & 75.8 \\
\hline Sexualization & & & 336 & 60.1 \\
\hline Other & & & 26 & 4.7 \\
\hline \multicolumn{5}{|l|}{$\begin{array}{l}\text { Did you start disliking their sponsors because they } \\
\text { were supporting sexist pro-players, teams, or } \\
\text { tournaments? }\end{array}$} \\
\hline Yes & & & 274 & 49 \\
\hline No & & & 285 & 51 \\
\hline
\end{tabular}

The findings confirmed $\mathrm{H}_{2}$ that sexism is a threat for esports sponsors. Particularly, sexism was labeled as a medium-risk threat for esports sponsors because most fans stated to have seen some form of sexism in esports and a significant percentage reported that they dislike the pro-players, teams, or tournaments connected to these acts (i.e. $42.9 \%$ ) or the brands that sponsor them $(49 \%)$.

The empirical data showed that most fans believe that there is a high lack of female pro-players. This is in line with several authors like CGC Europe (2015), Funk et al. (2018), Mooney (2018), SuperData (2015), and Winnan (2016), who mention that male pro-players have largely populated the esports scene. Also, the overwhelming majority of fans have seen sexist behaviors in esports. This is in accordance with Cunningham et al. (2018) and Winnan (2016), who state that sexism issues have become commonplace in esports. The type of sexist behaviors that have led more people to dislike pro-players, teams, or tournaments is undermining or devaluing. This is in sync 
with Kaye et al. (2018), Menti and Araújo (2017), and Misra and Danwani (2012), who mention that female pro-players are often underestimated or seen as worthless. Still, it was possible to see that a slight majority of fans have not disliked pro-players, teams, or tournaments that showed signs of sexism. This may be due to two factors. First, just like Menti and Araújo (2017), Winnan (2016), and Zolides (2015) state, the esports fan base is primarily dominated by males. If there were a higher percentage of females in the community, there would probably be a much higher percentage of fans disliking the pro-players, teams, or tournaments that exhibited sexist behaviors. Second, according to Winnan (2016), some esports fans have even defended that sexism is a natural element of esports. This shows that some fans see sexism as a normal component of the scene and do not condemn such acts. This may be why Winnan (2016) also mentions that esports is very unwelcome to women and why Menti and Araújo (2017) state that males' high presence in esports presents large barriers to female pro-players.

Furthermore, the fact that the empirical data showed that most fans do not dislike sexist pro-players, teams, or tournaments or their sponsors may be a clue for as to why Winnan (2016) declares that, although some efforts have been made to mitigate several of esports' issues, the issue of gender inequality has been largely ignored by most esports organizations. In other words, it could be that the issue of sexism has been overlooked because it has not caused significant backlashes from the fans. Nevertheless, like Ströh (2017) indicates, these sexism issues are still a threat to the sponsors' image. If news of the acceptance of sexism in esports is spread to the media, multiple sponsors may be severely affected.

Sponsors should see this as an opportunity to increase their involvement and relevancy in the esports scene. By promoting female participation and acceptance naturally and organically, sponsors will have increased chances of being positively perceived by both male and female esports fans. However, the creation of teams or tournaments exclusive to females should be avoided as this could have the opposite effect and further increase gender segregation. As esports is not a physical sport, there is no excuse for gendered teams or tournaments. In this respect, the best option would be to partner with tournaments that require teams to have at least one male and one female member.

\section{Illegal and Unregulated Gambling}

The data in Figure 4 shows that most fans have rarely or never seen evidence or acts of illegal or unregulated gambling in esports. However, the figure also reveals that most fans (i.e., $65.5 \%$ or $1,042 / 1,592$ ) have seen at least some form of illegal or unregulated gambling in esports. Table 5 indicates that, from this group, the majority does not dislike the pro-players, teams, or tournaments that were connected in some 
form to illegal or unregulated gambling. Still, a considerable percentage started disliking these entities. Regarding this latter group, the types of illegal or unregulated gambling that made them dislike these entities the most were: promotion of illegal or unregulated gambling websites or brands, promotion of illegal or unregulated skin buying websites or brands, promotion of underage gambling, and promotion of loot boxes. A less mentioned issue was the promotion of gambling in countries where betting is illegal. Moreover, the majority of esports fans stated that they started disliking the brands that were sponsoring the pro-players, teams, or tournaments connected to illegal or unregulated gambling.

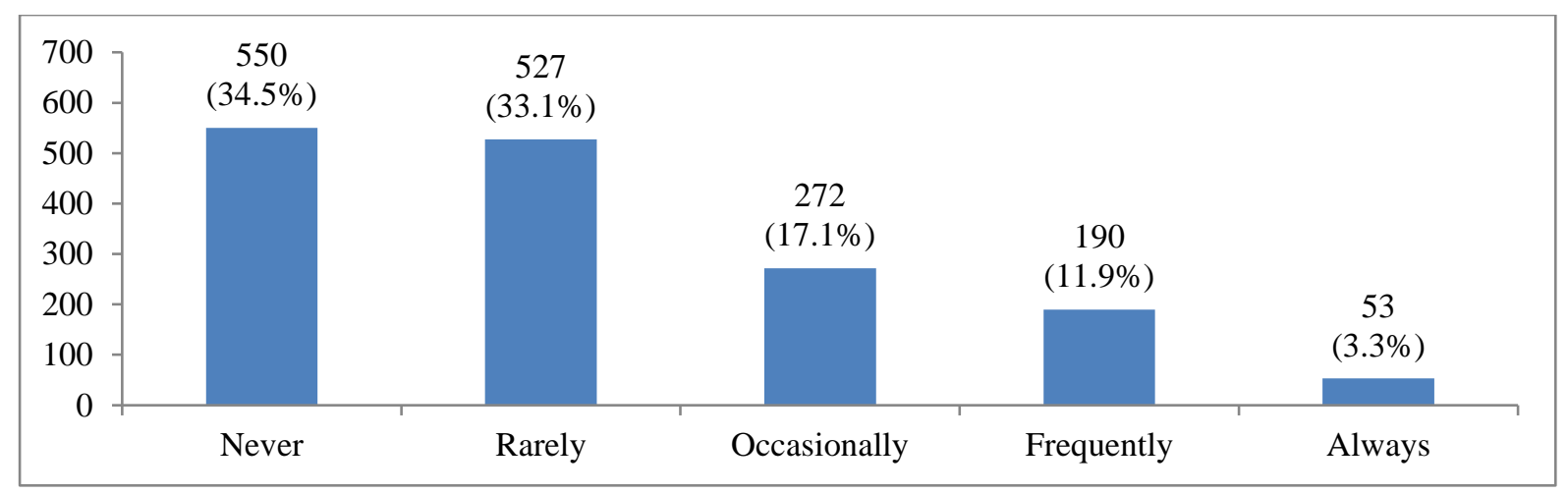

Figure 4 Fans' Frequency of Seeing Illegal and Unregulated Gambling in Esports 
Table 5 Illegal and Unregulated Gambling

\begin{tabular}{|c|c|c|c|}
\hline $\begin{array}{l}\text { Question } \\
\quad \text { Answer option }\end{array}$ & $\begin{array}{r}n= \\
1,042\end{array}$ & $n=406$ & $\begin{array}{r}\text { Valid } \\
\%\end{array}$ \\
\hline \multirow{2}{*}{\multicolumn{4}{|c|}{$\begin{array}{l}\text { Have you ever started disliking a pro-player, team, or } \\
\text { tournament because they were connected to illegal or } \\
\text { unregulated gambling? }\end{array}$}} \\
\hline & & & \\
\hline Yes & 406 & & 39 \\
\hline No & 636 & & 61 \\
\hline \multicolumn{4}{|l|}{$\begin{array}{l}\text { What types of illegal or unregulated gambling made you } \\
\text { dislike them? Select all that apply. }\end{array}$} \\
\hline Promoting underage gambling & & 257 & 63.3 \\
\hline Promoting gambling in countries where betting is illegal & & 96 & 23.6 \\
\hline $\begin{array}{l}\text { Promoting illegal or unregulated gambling websites or } \\
\text { brands }\end{array}$ & & 282 & 69.5 \\
\hline $\begin{array}{l}\text { Promoting illegal or unregulated skin buying websites or } \\
\text { brands }\end{array}$ & & 278 & 68.5 \\
\hline Promoting loot boxes & & 223 & 54.9 \\
\hline Other & & 54 & 13.3 \\
\hline \multicolumn{4}{|l|}{$\begin{array}{l}\text { Did you start disliking their sponsors because they were } \\
\text { supporting pro-players, teams, or tournaments } \\
\text { connected to illegal or unregulated gambling? }\end{array}$} \\
\hline Yes & & 224 & 55.2 \\
\hline No & & 182 & 44.8 \\
\hline
\end{tabular}

The data validated $\mathrm{H}_{3}$ that illegal and unregulated gambling is a threat for esports sponsors. Specifically, illegal and unregulated gambling was identified as a high-risk threat for esports sponsors because the majority of esports fans stated to have seen some form of this in esports, and most also indicated to dislike brands that sponsor the proplayers, teams, or tournaments connected to this illicit activity.

The empirical data showed that the majority of esports fans had seen some form of illegal or unregulated gambling in esports. This is in line with several sources of the literature like Griffiths (2017), Holden (2017), Holden, Rodenberg, et al. (2017), Shabir (2017), and Ströh (2017), who state that illegal esports wagering has become immensely popular and a serious issue. Still, it was unexpected to see that most fans do not dislike the pro-players, teams, or tournaments connected to illegal or unregulated gambling, and yet most of them dislike the brands that sponsor the aforementioned entities. There is a chance that fans do not develop negative feelings towards the pro-players, teams, and tournaments connected to illegal and unregulated gambling because some of the fans are also involved in esports gambling. Just like Griffiths (2017), Holden (2017), Holden, Rodenberg, et al. (2017), Shabir (2017), and Ströh (2017) mention, illegal esports betting is very popular. This could be the reason why fans have a high 
acceptance of others also being involved in this. However, this does not justify why most fans disliked the brands that sponsored the entities connected to these activities. At this moment, further research is needed to answer this question.

Nevertheless, the data clearly shows that brands who partner with entities connected to illegal or unregulated gambling are not well perceived. From all the types of disreputable behavior, this showed to be the one that brands should keep the greatest distance of. The connection to illegal and underage gambling may surround the brand in a PR nightmare of bad press and lead to backlashes from both esports fans and the general public.

\section{Match-Fixing}

As shown in Figure 5, the vast majority of esports fans have rarely or never seen match-fixing in esports. The figure also indicates that most fans (i.e., $64.2 \%$ or $1,022 / 1,592$ ) have seen at least some form of match-fixing in esports. According to Table 6, from this group, the majority dislikes pro-players, teams, or tournaments connected to match-fixing. The most cited types of match-fixing that led them to develop these negative feelings were opposing pro-players or teams agreeing on whom will win or lose the match and pro-players or teams betting against themselves and purposefully losing the match to win gambling money. Other less mentioned reasons included managers bribing or forcing pro-players or teams into purposefully losing the match and betting companies bribing pro-players or teams into purposefully losing the match. Even so, a small majority indicated not to dislike the brands that sponsored the pro-players, teams, or tournaments connected to match-fixing. Still, it must be mentioned that a very considerable percentage dislikes these brands.

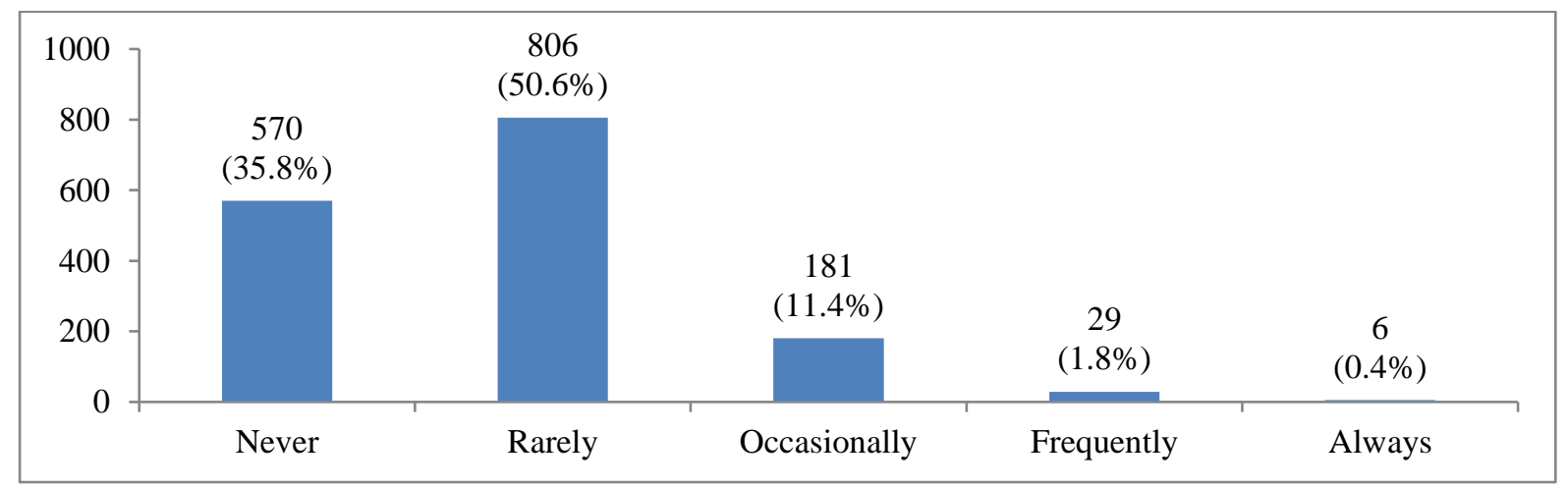

Figure 5 Fans' Frequency of Seeing Match-Fixing in Esports 
Table 6 Match-Fixing

\begin{tabular}{|c|c|c|c|}
\hline $\begin{array}{l}\text { Question } \\
\text { Answer option }\end{array}$ & $n=1,022$ & $n=694$ & $\begin{array}{c}\text { Valid } \\
\%\end{array}$ \\
\hline \multicolumn{4}{|l|}{$\begin{array}{l}\text { Have you ever started disliking a pro-player, team, or } \\
\text { tournament because they were connected to match- } \\
\text { fixing? }\end{array}$} \\
\hline Yes & 694 & & 67.9 \\
\hline No & 328 & & 32.1 \\
\hline \multicolumn{4}{|l|}{$\begin{array}{l}\text { What types of match-fixing made you dislike them? Select } \\
\text { all that apply. }\end{array}$} \\
\hline $\begin{array}{l}\text { Pro-players or teams betting against themselves and } \\
\text { purposefully losing the match in order to win } \\
\text { gambling money }\end{array}$ & & 433 & 62.4 \\
\hline $\begin{array}{l}\text { Opposing pro-players or teams agreeing on who will win } \\
\text { the match }\end{array}$ & & 437 & 63 \\
\hline $\begin{array}{l}\text { Managers bribing or forcing pro-players or teams into } \\
\text { purposefully losing the match }\end{array}$ & & 261 & 37.6 \\
\hline $\begin{array}{l}\text { Betting companies bribing pro-players or teams into } \\
\text { purposefully losing the match }\end{array}$ & & 234 & 33.7 \\
\hline Other & & 53 & 7.6 \\
\hline \multicolumn{4}{|l|}{$\begin{array}{l}\text { Did you start disliking their sponsors because they we } \\
\text { supporting pro-players, teams, or tournaments } \\
\text { connected to match-fixing? }\end{array}$} \\
\hline Yes & & 302 & 43.5 \\
\hline No & & 392 & 56.5 \\
\hline
\end{tabular}

The results confirmed $\mathrm{H}_{4}$ that match-fixing is a threat for esports sponsors. Particularly, match-fixing was labeled as a medium-risk threat for esports sponsors since most fans have seen some form of it in esports and referred to dislike the proplayers, teams, or tournaments connected to these acts. Still, the majority of fans did not report to dislike the brands that sponsor the entities connected to these acts.

The empirical data has shown that most esports fans have seen some form of match-fixing in esports. This is to be expected as both Mah (2011) and Winnan (2016) state that match-fixing has invaded esports, and Li (2016), Ströh (2017), and Winnan (2016) mention that this has caused several incidents and scandals. According to the empirical data, most fans have developed negative feelings towards the pro-players, teams, and tournaments connected to match-fixing. On the one hand, this could be related to esports gambling's immense popularity (Griffiths, 2017; Holden, 2017; Holden, Rodenberg, et al., 2017; Shabir, 2017; Ströh, 2017) and how match-fixing interferes with the fairness of it. On the other hand, it could be related to how matchfixing has ruined so many pro-players' careers, with some being arrested (Li, 2016; 
Ströh, 2017; Winnan, 2016) and others losing their lives (Stivers, 2017; Ströh, 2017). Interestingly, the majority of fans do not dislike the brands that sponsor the aforementioned entities connected to match-fixing. Despite this, Winnan (2016) mentions that the match-fixing incidents have led to the termination of several sponsorships.

From the brands' point of view, it makes complete sense to move away from entities connected to match-fixing. Being connected to scandals like the suicide of young players is something that cannot be easily forgotten. Sponsorship managers would do well to analyze which teams, players, or even team managers have a history of match-fixing and avoid partnering with these entities.

\section{Cheating}

According to Figure 6, most esports fans have rarely seen cheating in esports (the cheating in this subchapter does not include cyberattacks and doping). The figure also shows that most fans (i.e., $80.6 \%$ or $1,283 / 1,592$ ) have seen at least some form of cheating in esports. Table 7 shows that, from this group, the overwhelming majority has started disliking a pro-player, team, or tournament that was connected to cheating. The cheating types that led esports fans to dislike them the most were using software to cheat and exploit in-game bugs or glitches. Other less mentioned forms of cheating included using modified hardware and macros. However, most esports fans do not dislike the brands that sponsor the pro-players, teams, or tournaments connected to cheating. Still, a relevant percentage started disliking these aforementioned entities.

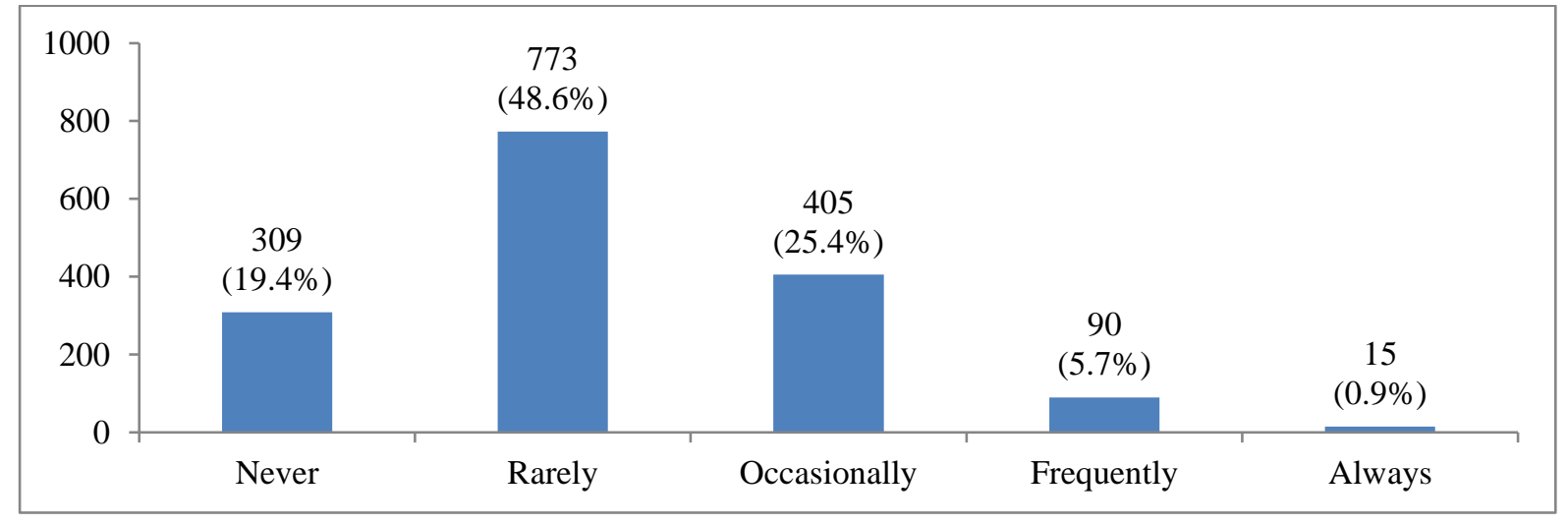

Figure 6 Fans' Frequency Of Seeing Cheating In Esports (Not Including Doping And Cyberattacks) 
Table 7 Cheating

\begin{tabular}{|c|c|c|c|}
\hline Question & $n=$ & $n=$ & $\begin{array}{r}\text { Valid } \\
\%\end{array}$ \\
\hline Answer option & 1,283 & 1,030 & \\
\hline \multicolumn{4}{|c|}{$\begin{array}{l}\text { Have you ever started disliking a pro-player, team, or } \\
\text { tournament because they were connected to cheating } \\
\text { (not including doping)? }\end{array}$} \\
\hline Yes & 1,030 & & 80.3 \\
\hline No & 253 & & 19.7 \\
\hline \multicolumn{4}{|c|}{$\begin{array}{l}\text { What types of cheating made you dislike them (not including } \\
\text { doping)? Select all that apply. }\end{array}$} \\
\hline Using software to cheat & & 883 & 85.7 \\
\hline Exploiting in-game bugs/glitches & & 437 & 42.4 \\
\hline Using macros & & 367 & 35.6 \\
\hline Using modified hardware & & 374 & 36.3 \\
\hline Other & & 102 & 9.9 \\
\hline \multicolumn{4}{|c|}{$\begin{array}{l}\text { Did you start disliking their sponsors because they were } \\
\text { supporting pro-players, teams, or tournaments } \\
\text { connected to cheating (not including doping)? }\end{array}$} \\
\hline Yes & & 367 & 35.6 \\
\hline No & & 663 & 64.4 \\
\hline
\end{tabular}

The findings supported $\mathrm{H}_{5}$ that cheating is a threat for esports sponsors. Specifically, cheating was labeled as a medium-risk threat for esports sponsors since most fans have seen some form of it in esports and referred to dislike the pro-players, teams, or tournaments connected to these acts. Yet, the majority of fans do not dislike the brands that sponsor entities connected to these activities.

Most esports fans have seen cheating in esports. This is in line with Winnan (2016), who mentions that there have been several cheating scandals and that it is easy to identify cheaters in competitive gaming. The majority of fans also stated that they disliked pro-players, teams, or tournaments connected to cheating. This data is supported by Ströh (2017), who refers that cheating damages the esports experience and decreases the number of viewers, and by Winnan (2016) who states that cheating has led esports fans to create a lot of backlash on the cheaters' social media webpages.

Interestingly, cheating has not led most fans to dislike the sponsors of the aforementioned cheating entities. However, brands should keep their guard up when searching for esports entities to sponsor and when maintaining these partnerships. Having a large number of fans flooding a pro-player's social media with angry comments while his profile picture shows him wearing a jersey with the sponsor's logo may have a high probability of leading to negative brand image transfer. 


\section{Cyberattacks}

As Figure 7 points out, most esports fans have never seen cyberattacks in esports. Still, a relevant percentage (i.e., $47.3 \%$ or $753 / 1,592$ ) has seen some form of cheating in this industry. According to Table 8, from this latter group, although most stated that they do not dislike the pro-players, teams, or tournaments connected to cyberattacks, a significant percentage still indicated to dislike the aforementioned entities. Likewise, although most declared to not dislike the brands that sponsor the pro-players, teams, or tournaments connected to cyberattacks, a significant percentage still stated to dislike these entities.

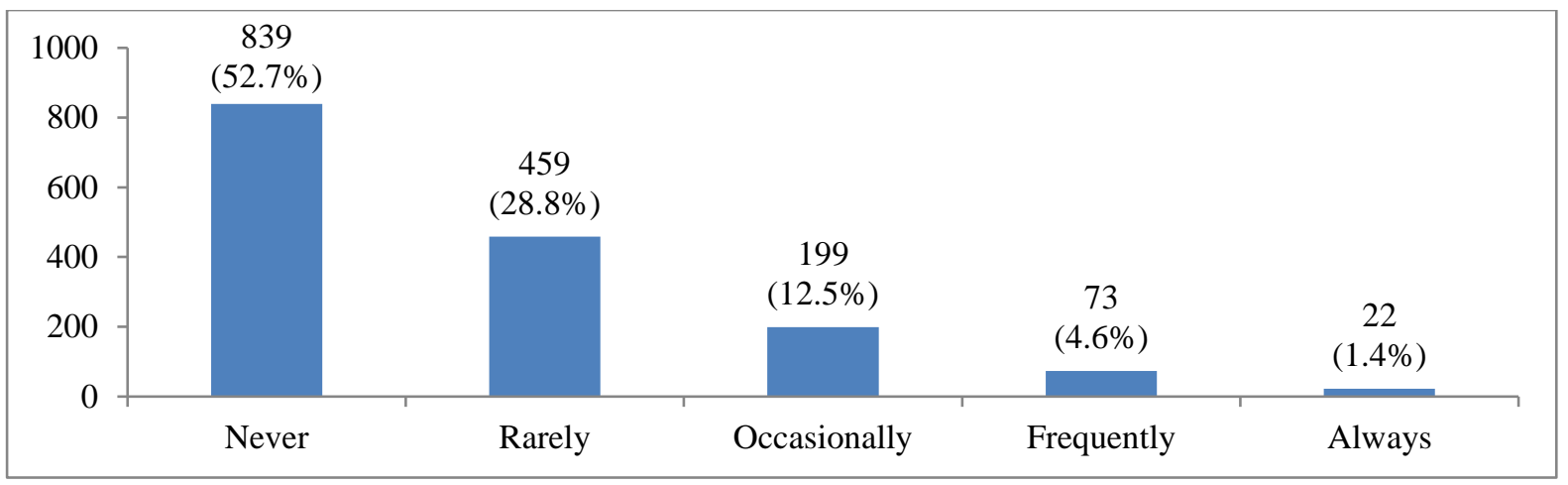

Figure 7 Fans' Frequency of Seeing Cyberattacks in Esports

Table 8 Cyberattacks

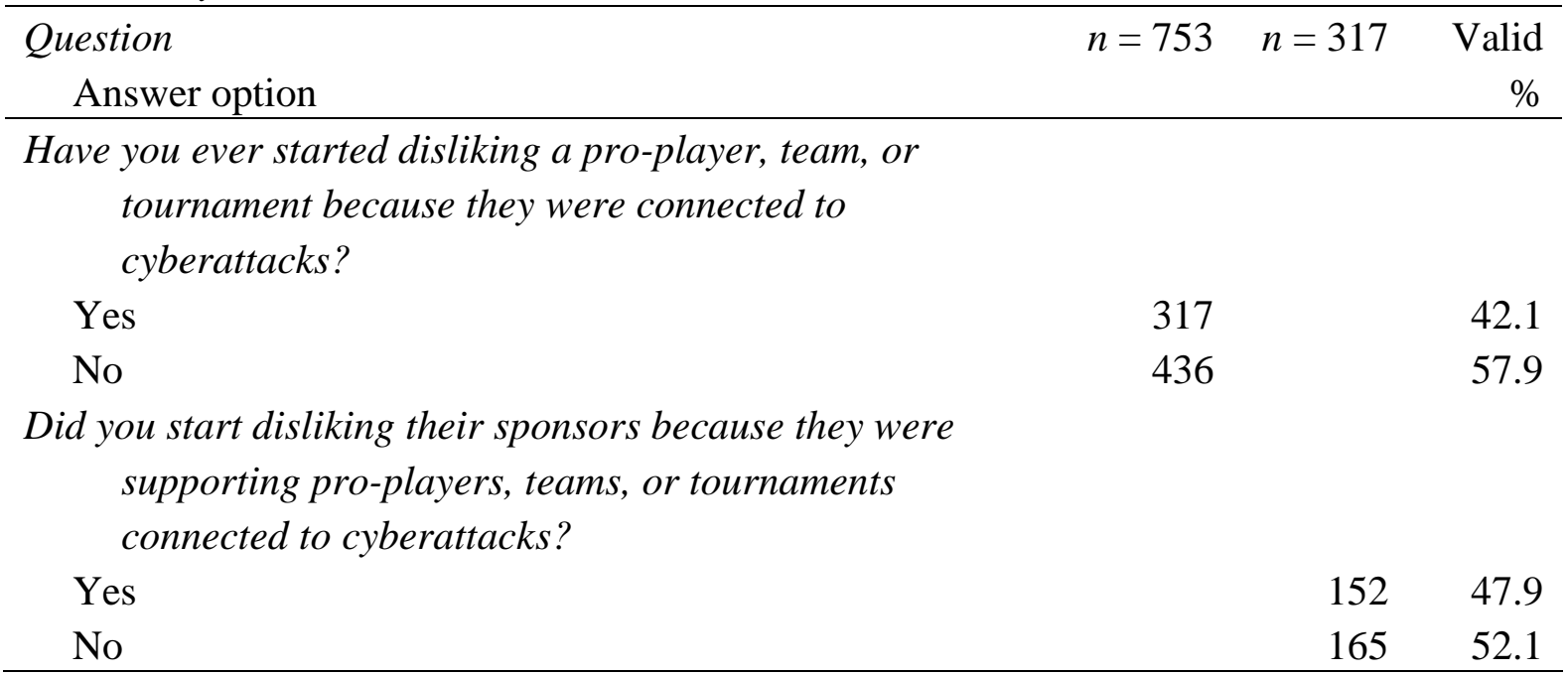

The data validated $\mathrm{H}_{6}$ that cyberattacks are a threat for esports sponsors. Particularly, cyberattacks were found to be a low-risk threat for esports sponsors. Despite not being in the majority, a very significant percentage of fans still reported that they have seen some form of cyberattacks in esports (i.e., 47.3\%) or that they have disliked the pro-players, teams, or tournaments connected to these acts (i.e., 42.1\%) or the brands that sponsor them $(47.9 \%)$. 
Although most fans indicated that they have never seen cyberattacks in esports, it is interesting that Winnan (2016) states that it is easy to identify cheating in esports (with cyberattacks being a form of cheating). It could be that cyberattacks are a not very common form of cheating. This would also justify why there is such small literature on cyberattacks in esports. Likewise, although the empirical data showed that most fans do not dislike the pro-players, teams, or tournaments connected to cyberattacks nor their sponsors, Ströh (2017) mentions that cyberattacks heavily influence matches and the esports betting market. Considering how big the esports gambling market has become (Griffiths, 2017; Holden, 2017; Holden, Rodenberg, et al., 2017; Shabir, 2017; Ströh, 2017), it is unexpected to see most fans not disliking the entities connected to cyberattacks.

One justification for this could be connected to the fact that cyberattacks have to be conducted by a third party. The pro-player who is busy competing cannot conduct a cyberattack at the same time he is playing the game. This also means that the threat of a brand being negatively affected for sponsoring entities connected to cyberattacks is low, yet not impossible. To prevent any sort of cyberattacks brands should only sponsor offline tournaments and even then only those with a high enough pedigree to have a highly secure virtual infrastructure that cannot be affected by cyberattacks.

\section{Doping}

In Figure 8 it is possible to see that the majority of esports fans have never seen evidence or acts of doping in esports. Still, a relevant percentage (i.e., 39\% or 621/1,592) has seen some form of doping in esports. According to Table 9, from this latter group, the majority indicated to not dislike the pro-players, teams, or tournaments connected to doping. Only a small percentage dislikes these entities. From those who developed these negative feelings, most defended that they do not dislike the brands that sponsor the pro-players, teams, or tournaments connected to doping. Still, a considerable percentage declared to dislike the brands that sponsor the aforementioned entities.

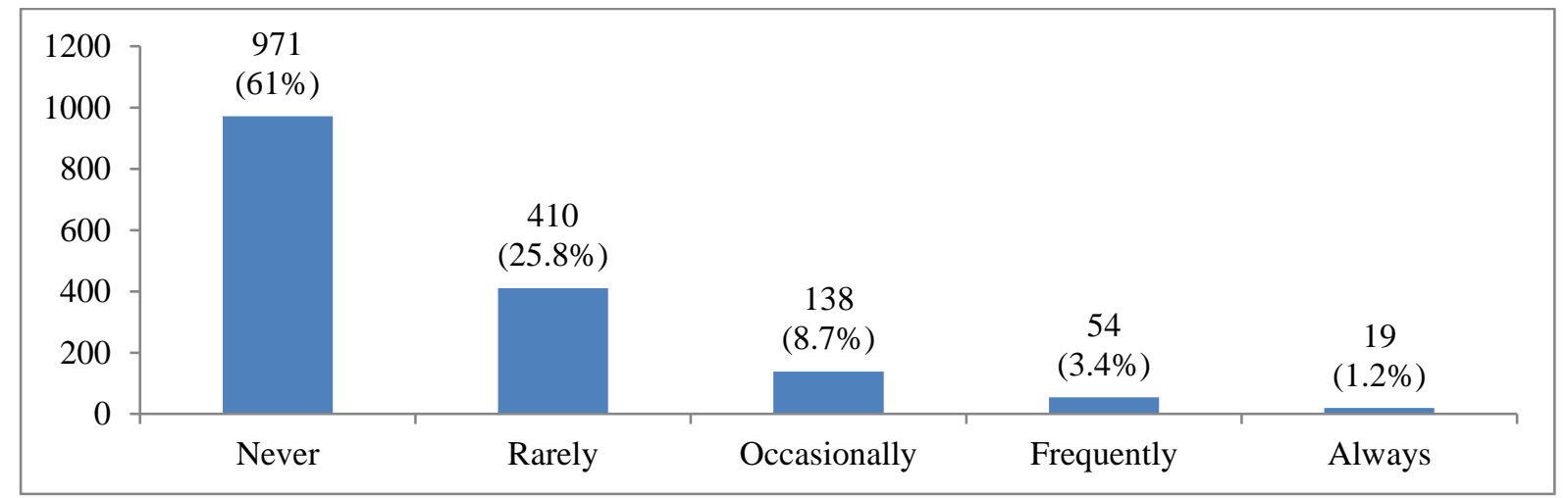

Figure 8 Fans' Frequency of Seeing Doping in Esports 
Table 9 Doping

\begin{tabular}{|c|c|c|c|}
\hline $\begin{array}{l}\text { Question } \\
\text { Answer option }\end{array}$ & $n=621$ & $n=153$ & $\begin{array}{r}\text { Valid } \\
\% \\
\end{array}$ \\
\hline \multicolumn{4}{|c|}{$\begin{array}{l}\text { Have you ever started disliking a pro-player, team, or } \\
\text { tournament because they were connected to doping? }\end{array}$} \\
\hline Yes & 153 & & 24.6 \\
\hline No & 468 & & 75.4 \\
\hline \multicolumn{4}{|c|}{$\begin{array}{l}\text { Did you start disliking their sponsors because they we } \\
\text { supporting pro-players, teams, or tournaments } \\
\text { connected to doping? }\end{array}$} \\
\hline Yes & & 61 & 39.9 \\
\hline No & & 92 & 60.1 \\
\hline
\end{tabular}

The results confirmed $\mathrm{H}_{7}$ that doping is a threat for esports sponsors. Specifically, doping was found to be a low-risk threat for esports sponsors. Despite not being in the majority, a significant percentage of fans stated to have seen some form of doping in esports (i.e., 39\%), as well as disliking the pro-players, teams, or tournaments connected to these acts (i.e., 24.6\%) or the brands that sponsor them (i.e., 39.9\%).

The empirical data is not in accordance with the literature. While most of the sample has never seen doping in esports, Stivers (2017) and Winnan (2016) state that the topic of doping in esports has attracted a lot of attention. Maybe most of this attention has emerged from the general media and not so much from the esports community. In the same vein, despite the majority of fans indicating that they do not dislike the pro-players, teams, or tournaments connected to doping, Holden et al. (2018) state that doping has caused several scandals. Lastly, even though most fans did not dislike the brands that sponsored the entities connected to doping, Winnan (2016) refers that doping in esports has created a lot of negative press. It could be that most of this attention, scandals, and negative press have happened on the general media and not so much on the esports-specific press and forums.

Despite being seen as a low-risk threat, the contradictory data should serve as a signal that doping may cause more harm than what is initially foreseen. Like with regular sports, esports sponsors would do well to quickly terminate partnerships with any entity connected to doping and release a public statement on how they do not support acts that are detrimental to both health and fair play.

\section{CONCLUSIONS}

In this research, it was possible to identify seven disreputable behavior-related threats that esports sponsors must be cautious about. Figure 9 presents the empirical model that resulted from combining the literature review and empirical data. 
Specifically, it was possible to identify one high-risk threat, four medium-risk threats, and two low-risk threats. As the figure shows, the higher up the type, or subtype, of disreputable behavior is, the more threatening it is for the esports sponsor.

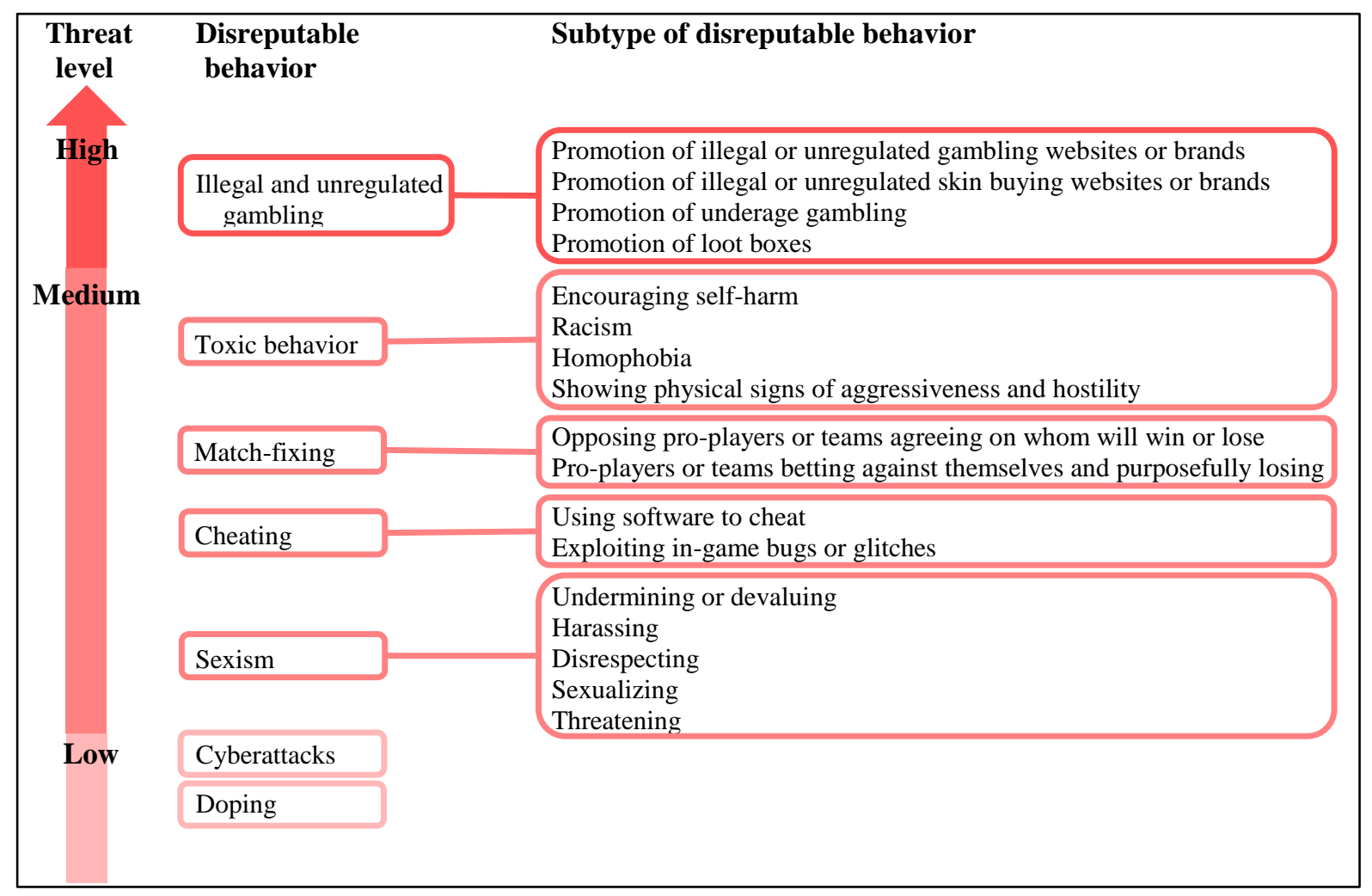

Figure 9 Most Threatening Forms of Disreputable Behavior for Esports Sponsors (Empirical Model)

It is vital to mention that all of the threats covered in this research present risks to the sponsors but, in terms of negative fan reactions, some proved to be more threatening than others. Also, although most of the fans stated that they do not dislike the sponsors associated with most of these threats, it should still be mentioned that, whenever fans start to dislike the sponsored party, there is a chance of them unconsciously developing negative emotions towards the things that are associated with them, and this includes their sponsors. This is known as brand image transfer (Lacey \& Close, 2013; Yang \& $\mathrm{Ha}, 2014)$. Hence, even the medium and low-risk threats present severe dangers to the sponsors.

The low-risk threats should not be underestimated. Although most fans referred that they do not dislike the entities connected to these acts or the brands that sponsor them, these threats can still severely damage the sponsors' image. For instance, Ströh (2017) states that esports' issues of sexism may be spread by the media, which will severely damage the general esports' image and the image of its sponsors. Likewise, 
Winnan (2016) mentions that doping has generated a lot of negative press, which threatens all esports stakeholders.

In general, this study showed which types of disreputable behavior esports sponsors should be most wary of. For instance, the data showed that, since doping and cyberattacks are classified as low-risk behaviors, these have less chance of negatively affecting the esports sponsors' brand image. As such, when these behaviors are verified, the immediate termination of the partnerships may not be necessary, and a warning to the sponsored party may suffice. On the other hand, the research also showed that if the sponsored party is found to be involved in a high-risk type of behavior, like illegal or unregulated gambling, the sponsorship should be quickly terminated as the study found that most esports fans will develop negative feelings towards brands that sponsor esports entities connected to this. Brand image is one of the most valuable assets of any brand, and this study helps esports sponsors in maintaining their prestige.

\section{LIMITATIONS AND FUTURE RESEARCH}

The minuscule literature on esports and esports sponsorships significantly limited the research. The quantitative approach also restricted the esports fans' ability to vocalize their opinions on the subject matter. The research analyzed the risk level of disreputable behavior-related threats solely from the esports fans' point of view. This means that it did not perform an empirical analysis of how the general media or general public may react to seeing a brand sponsoring esports entities connected to a form of disreputable behavior. These aspects should be further researched.

Moreover, although sexism was identified as a low-risk threat, it should be mentioned that $91.7 \%$ of the sample was composed of males, which inserts some severe bias into this specific topic. It is very probable that if more females had been part of the sample, the issue of sexism would have been seen as a higher-level threat. Nevertheless, the sample's male-to-female ratio is very close to the $10 \%$ of female fans that Zolides (2015) states.

The general field of esports is in dire need of more research, especially the topic of its weaknesses and threats. Future studies related to disreputable behavior in esports would benefit from using qualitative methods to gather more rich data that could justify some of the questions raised in this paper. For instance, why do fans dislike the brands that sponsor entities connected to illegal and unregulated gambling but not entities connected to toxic behaviors, cheating, sexism, or match-fixing? A similar study in the future will also allow analyzing if these behaviors are becoming more or less frequent and if there are any changes in the threat level that each presents to sponsors. Finally, contrary to this research which analyzed the entire esports scene, it would be useful to 
analyze if the threat level of each type of disreputable behavior varies according to each different esports title.

\section{ACKNOWLEDGEMENTS}

This work was supported by the Fundação para a Ciência e a Tecnologia (FCT) and the European Social Fund (ESF). The recipient is Bruno Duarte Abreu Freitas and the grant number is SFRH/BD/143227/2019.

\section{REFERENCES}

AEVI. (2018). Libro blanco de los esports en España. http://www.aevi.org.es/web/wp -content/uploads/2018/05/ES_libroblanco_online.pdf

Albrecht, S. W., Howe, K. R., \& Rommey, M. (1984). Deterring Fraud: The Internal Auditors' Perspective. Altamonte Springs: Institute of Auditors Research Foundation.

Billings, A. C., Rodgers, E. B. D., Rodgers, R. P., \& Wiggins, B. P. (2019). Esports Spectator Motivation. In R. Rogers (Ed.), Understanding Esports: An Introduction to the Global Phenomenon (pp. 73-84). London: Rowman \& Littlefield.

Blackburn, J., \& Kwak, H. (2014). STFU NOOB! Predicting Crowdsourced Decisions on Toxic Behavior in Online Games. In C.-W. Chung, A. Broder, K. Shim \& T. Suel (Eds.), Proceedings of the 23rd international conference on World wide web (pp. 877-888). New York, NY: Association for Computing Machinery. : https://doi.org/10.1145/2566486.2567987

Brenda, H. K. S. (2017). Spectating the Rift: A Study into eSports Spectatorship. In J. Hiltscher \& T. M. Scholz (Eds.), eSports Yearbook 2015/16 (pp. 9-35).

Norderstedt: Books on Demand GmbH. http://www.esportsyearbook.com/eyb201516.pdf

Brickell, A. (2017). Addressing integrity and regulatory risks in esports: The responsibility of the whole esports community. Gaming Law Review, 21(8), 603609. https://doi.org/10.1089/glr2.2017.21810

Brooks, G., Aleem, A., \& Button, M. (2013). Fraud, Corruption and Sport. Hampshire: Palgrave Macmillan.

Callus, P., \& Potter, C. (2017). Michezo Video: Nairobi's gamers and the developers who are promoting local content. Critical African Studies, 9(3), 302-326. https://doi.org/10.1080/21681392.2017.1371620

CGC Europe. (2015). Marketing Channel eSports - How to get the attention of young adults? http://docplayer.net/12867287-Marketing-channel-esports-how-to-getthe-attention-of-young-adults.html 
Chalmet, X. (2015). Sponsorship within Esports: Examining the Sponsorship Reationship Quality Constructs. (Master Thesis), University of Gothenburg, Gothenburg.

https://gupea.ub.gu.se/bitstream/2077/39848/1/gupea_2077_39848_1.pdf

Christophers, J. (2011). Why Cheating Is A Crime - The ESL Wire Story. In J.

Christophers \& T. M. Scholz (Eds.), eSports Yearbook 2010 (pp. 90-96).

Norderstedt: Books on Demand GmbH. http://esportsyearbook.com/eyb2010.pdf

Cohen, L., Manion, L., \& Morrison, K. (2018). Research Methods in Education (8th ed.). Abingdon: Routledge.

Collin, P. H. (Ed.). (2003). Easier English Student Dictionary (2nd ed.). London: Bloomsbury Publishing Plc.

Cressey, D. R. (1973). Other People's Money: A Study in the Social Psychology of Embezzlement. Montclair: Patterson Smith.

Crompton, J. (1994). Benefits and Risks Associated with Sponsorship of Major Events. Festival Management and Event Tourism, 2(2), 65-74.

https://doi.org/10.3727/106527094792292050

Crompton, J. L. (2015). Potential negative outcomes from sports sponsorship. International Journal of Sports Marketing and Sponsorship, 16(3), 20-34. https://doi.org/10.1108/IJSMS-16-03-2015-B003

Cunningham, G. B., Fairley, S., Ferkins, L., Kerwin, S., Lock, D., Shaw, S., \& Wicker, P. (2018). eSport: Construct specifications and implications for sport management. Sport Management Review, 21(1), 1-6.

https://doi.org/10.1016/j.smr.2017.11.002

ESA. (2017). 2016 Annual Report. http://www.theesa.com/wpcontent/uploads/2017/09/ESA-AnnualReport-Digital-91917.pdf

Esports Earnings. (2020). Top Games Awarding Prize Money. Retrieved 28 January, 2020, https://www.esportsearnings.com/games

Funk, D. C., Pizzo, A. D., \& Baker, B. J. (2018). eSport management: Embracing eSport education and research opportunities. Sport Management Review, 21(1), 7-13. https://doi.org/10.1016/j.smr.2017.07.008

Gainsbury, S. M., Abarbanel, B., \& Blaszczynski, A. (2017a). Game on: comparison of demographic profiles, consumption behaviors, and gambling site selection criteria of esports and sports bettors. Gaming Law Review, 21(8), 575-587. https://doi.org/10.1089/glr2.2017.21813

Gainsbury, S. M., Abarbanel, B., \& Blaszczynski, A. (2017b). Intensity and gambling harms: exploring breadth of gambling involvement among esports bettors. Gaming Law Review, 21(8), 610-615. https://doi.org/10.1089/glr2.2017.21812 Gifford, C. (2017). Gaming Record Breakers. London: Carlton Books Limited. 
Goetomo, F. (2017). eSports in Korea: A Study on League of Legends Team Performances on the Share Price of Owning Corporations. In J. Hiltscher \& T. M. Scholz (Eds.), eSports Yearbook 2015/16 (pp. 79-94). Norderstedt: Books on Demand GmbH. http://www.esportsyearbook.com/eyb201516.pdf

Griffiths, M. (2017, January). The psychosocial impact of professional gambling, professional video gaming \& eSports. Casino \& Gaming International, 28, 5963. http://irep.ntu.ac.uk/id/eprint/30079

Hiltscher, J., \& Scholz, T. M. (2017). Preface. In J. Hiltscher \& T. M. Scholz (Eds.), eSports Yearbook 2015/16 (pp. 7-8). Norderstedt: Books on Demand GmbH. http://www.esportsyearbook.com/eyb201516.pdf

Holden, J. T. (2017). Trifling and Gambling with Virtual Money. UCLA Entertainment Law Review, Forthcoming, 1-43. http://dx.doi.org/10.2139/ssrn.3035892

Holden, J. T., \& Ehrlich, S. C. (2017). Esports, Skins Betting, and Wire Fraud Vulnerability. Gaming Law Review, 21(8), 566-574. https://doi.org/10.1089/glr2.2017.2183

Holden, J. T., Kaburakis, A., \& Rodenberg, R. (2017). The Future Is Now: Esports Policy Considerations and Potential Litigation. Journal of Legal Aspects of Sport, 27(1), 46-78. https://doi.org/10.1123/jlas.2016-0018

Holden, J. T., Kaburakis, A., \& Rodenberg, R. M. (2018). Esports: Children, stimulants and video-gaming-induced inactivity. Journal of Paediatrics and Child Health. https://doi.org/10.1111/jpc.13897

Holden, J. T., Rodenberg, R. M., \& Kaburakis, A. (2017). Esports Corruption: Gambling, Doping, and Global Governance. Maryland Journal of International Law, 32(1), 236-273. https://doi.org/10.2139/ssrn.2831718

Jenny, S. E., Keiper, M. C., Taylor, B. J., Williams, D. P., Gawrysiak, J., Manning, R. D., \& Tutka, P. M. (2018). eSports Venues: A New Sport Business Opportunity. Journal of Applied Sport Management, 10(1), 34-49.

https://doi.org/10.18666/JASM-2018-V10-I1-8469

Kaye, L. K., Pennington, C. R., \& McCann, J. J. (2018). Do casual gaming environments evoke stereotype threat? Examining the effects of explicit priming and avatar gender. Computers in Human Behavior, 78, 142-150. https://doi.org/10.1016/j.chb.2017.09.031

Keiper, M. C., Manning, R. D., Jenny, S., Olrich, T., \& Croft, C. (2017). No reason to LoL at LoL: the addition of esports to intercollegiate athletic departments. Journal for the Study of Sports and Athletes in Education, 11(2), 143-160. https://doi.org/10.1080/19357397.2017.1316001 
Korpimies, S. (2017). Sponsorships in eSports. (Bachelor thesis), Aalto University, Espoo. http://urn.fi/URN:NBN:fi:aalto-201705114490

Kozachuk, J., Foroughi, C. K., \& Freeman, G. (2016). Exploring electronic sports: An interdisciplinary approach. Proceedings of the Human Factors and Ergonomics Society 2016 Annual Meeting, 60(1), 2118-2122.

https://doi.org/10.1177/1541931213601479

Kuhn, K. A. L. (2009). The Market Structure and Characteristics of Electronic Games. In N. K. L. Pope, K.-A. L. Kuhn \& J. J. H. Forster (Eds.), Digital Sport for Performance Enhancement and Competitive Evolution: Intelligent Gaming Technologies (pp. 257-285). London: Information Science Reference. https://doi.org/10.4018/978-1-60566-406-4.ch016

Lacey, R., \& Close, A. G. (2013). How fit connects service brand sponsors with consumers' passions for sponsored events. International Journal of Sports Marketing and Sponsorship, 14(3), 57-73. https://doi.org/10.1108/IJSMS-14-032013-B005

Lee, J. (2017, 27 November). 3 Awesome Social Networks Just for Gamers. Retrieved 19 October, 2019, https://www.makeuseof.com/tag/3-awesome-social-networksjust-for-gamers/

Li, R. (2016). Good luck have fun: the rise of eSports. New York, NY: Skyhorse Publishing.

Lieberman, A., \& Esgate, P. (2002). The Entertainment Marketing Revolution: Bringing the Moguls, the Media, and the Magic to the World. New Jersey, NJ: Financial Times Prentice Hall.

Lokhman, N., Karashchuk, O., \& Kornilova, O. (2018). Analysis of eSports as a commercial activity. Problems and Perspectives in Management, 16(1), 207-213. http://dx.doi.org/10.21511/ppm.16(1).2018.20

Mah, J. (2011). The Globe of eSports: Our Cultures, Our Worlds. In J. Christophers \& T. M. Scholz (Eds.), eSports Yearbook 2010 (pp. 62-69). Norderstedt: Books on Demand GmbH. http://esportsyearbook.com/eyb2010.pdf

Manoli, A. E. (2018). Sport marketing's past, present and future; an introduction to the special issue on contemporary issues in sports marketing. Journal of Strategic Marketing, 26(1), 1-5. https://doi.org/10.1080/0965254X.2018.1389492

Martinelli, D. (2017). Skin gambling: Have we found the millennial goldmine or imminent trouble? Gaming Law Review, 21(8), 557-565. http://doi.org/10.1089/glr2.2017.21814

Menasce, R. M. (2019). From Casual to Professional: How Brazilians Achieved eSports Success in Counter-Strike: Global Offensive. In J. Hiltscher \& T. M. 
Scholz (Eds.), eSports Yearbook 2017/18 (pp. 121-140). Norderstedt: Books on Demand GmbH.

Menti, D. C., \& Araújo, D. C. d. (2017). Violência de gênero contra mulheres no cenário dos eSports. Conexão - Comunicação e Cultura, 16(31), 73-88.

https://doi.org/10.18226/21782687.v16.n31.03

Merriam-Webster. (2016). Merriam-Webster's advanced learner's English dictionary. Springfield, MA: Merriam-Webster, Incorporated.

Misra, A., \& Danwani, A. (2012). The world of eSports - Through a Girl Gamer's

Eye. In J. Christophers \& T. M. Scholz (Eds.), eSports Yearbook 2011/12 (pp. 59-61). Norderstedt: Books on Demand GmbH.

http://esportsyearbook.com/eyb201112.pdf

Mooney, C. (2018). Inside the E-Sports Industry. North Mankato, MN: Norwood House Press.

Neto, J. A. M., Yokoyama, K. M., \& Becker, K. (2017). Studying Toxic Behavior Influence and Player Chat in an Online Video Game. In A. P. Sheth, A. Ngonga, Y. Wang, E. Chang, D. Slezak, B. Franczyk, R. Alt, X. Tao \& R. Unland (Eds.), Proceedings of the International Conference on Web Intelligence (pp. 26-33).

New York, NY: ACM. https://doi.org/10.1145/3106426.3106452

Newzoo. (2016, March). Free 2016 Global Esports Market Report: An Overview of the Esports Market \& its Valuable Audience. http://resources.newzoo.com/2016esports-market-and-esports-audience

Newzoo. (2018, 21 February). Free 2018 Global Esports Market Report.

http://resources.newzoo.com/2018-global-esports-market-report-light

Newzoo. (2020). Most viewed games.

https://platform.newzoo.com/rankings/streaming

Nielsen Esports. (2017). The Esports Playbook: Maximizing your investment through understanding the fans. N. Pike \& S. Master (Eds.), http://www.nielsen.com/us/en/insights/reports/2017/the-esports-playbookmaximizing-investment-through-understanding-the-fans.html

Owens, M. D. (2016). What's in a Name? eSports, Betting, and Gaming Law. Gaming Law Review and Economics, 20(7), 567-570.

https://doi.org/10.1089/glre.2016.2075

Peša, A. R., Čičin-Šain, D., \& Blažević, T. (2017). New business model in the growing e-sports industry. Poslovna Izvrsnost: Znanstveni Časopis za Promicanje Kulture Kvalitete i Poslovne Izvrsnosti, 11(2), 121-131. https://doi.org/10.22598/pi-be/2017.11.2.121

Scholz, T. M. (2019). eSports is Business: Management in the World of Competitive Gaming. Switzerland: Springer Nature. 
Shabir, N. (2017). Esports: The Complete Guide 17/18: A guide for gamers, teams, organisations and other entities in, or looking to get into the space. Wroclaw: Independently published.

Statista. (2019, February). eSports audience size worldwide from 2012 to 2020, by type of viewers (in millions). https://www.statista.com/statistics/490480/globalesports-audience-size-viewer-type/

Stein, V., \& Scholz, T. M. (2016). Sky is the Limit - Esports as Entrepreneurial Innovator for Media Management. In S. N. d. Jesus \& P. Pinto (Eds.), Proceedings of the International Congress on Interdisciplinarity in Social and Human Sciences (pp. 622-631). Faro: University of Algarve. CIEO - Research Centre for Spatial and Organizational Dynamics. http://hdl.handle.net/10400.1/9888

Stivers, C. (2017). The First Competitive Video Gaming Anti-Doping Policy and Its Deficiencies Under European Union Law. San Diego International Law Journal, 18(2), 263-294. http://digital.sandiego.edu/ilj/vol18/iss2/4/

Ströh, J. H. A. (2017). The eSports Market and eSports Sponsoring. Marburg: Tectum Verlag.

SuperData. (2015, May). eSports: The market brief 2015.

https://pt.scribd.com/document/269675603/ESports-Market-Brief-2015-

SuperData-Research

Sylvester, R., \& Rennie, P. (2017). The world's fastest-growing sport: maximizing the economic success of esports whilst balancing regulatory concerns and ensuring the protection of those involved. Gaming Law Review, 21(8), 625-629. https://doi.org/10.1089/glr2.2017.21811

Winnan, C. D. (2016). An Entrepreneur's Guide to the Exploding World of eSports: Understanding the Commercial Significance of Counter-Strike, League of Legends and DotA 2. Kindle eBook: The Borderland Press.

Yang, S., \& Ha, S. (2014). Brand knowledge transfer via sponsorship in the financial services industry. Journal of Services Marketing, 28(6), 452-459.

https://doi.org/10.1108/JSM-11-2013-0313

Zolides, A. (2015). Lipstick Bullets: Labour and Gender in Professional Gamer SelfBranding. Persona Studies, 1(2), 42-53. https://doi.org/10.21153/ps2015vol1no2art467

Mr. Bruno Duarte Abreu Freitas (Corresponding author) completed his Bachelor Degree in Languages and Business Relations and his Master Degree in Cultural Management (where he was the best of his class) at the University of Madeira. Having gained a large interest for the 
fields of marketing, management and entrepreneurship, Bruno decided to research the new and emerging market of esports and is now doing his $\mathrm{PhD}$ thesis on esports sponsorships at the University of Vic - Central University of Catalonia (UVic-UCC). Bruno has also presented and published several papers on the esports market.

Dr. Ruth S. Contreras-Espinosa is a full-time $\mathrm{PhD}$ professor at the University of Vic - Central University of Catalonia (UVic-UCC). Co-founder and coordinator of the Observatory of Communication, Video Games and Entertainment INCOM, at the Autonomous University of Barcelona and UVic-UCC, a multi-disciplinary research group established on April 2014. She has been collaborating with international organizations in a huge variety of projects such as external evaluator at the Portuguese Agency of Evaluation and Accreditation (A3ES) and as a Member of the scientific advisory board on Brazilian Symposium on Computer Games and Digital Entertainment (SBGames).

Dr. Pedro A. Pereira Correia has a $\mathrm{PhD}$ in Interactive Digital Communication and Marketing (University of Vic), and he is Lecturer at the University of Madeira and ISAL, Funchal, Portugal. Member of Research Center CiTUR - Center for Research, Development and Innovation in Tourism. External Senior Expert to support the implementation of the European Structural and Investment Funds (2018). A major player in numerous operations and projects with proven multi-disciplinary and management skills. Extensive marketing and social media knowledge. 